\title{
Sinorhizobium fredii HH103 rkp-3 Genes Are Required for K-Antigen Polysaccharide Biosynthesis, Affect Lipopolysaccharide Structure and Are Essential for Infection of Legumes Forming Determinate Nodules
}

\author{
Isabel Margaret, ${ }^{1}$ Juan C. Crespo-Rivas, ${ }^{1}$ Sebastián Acosta-Jurado, ${ }^{1}$ Ana M. Buendía-Clavería, ${ }^{1}$ \\ María T. Cubo, ${ }^{1}$ Antonio Gil-Serrano, ${ }^{2}$ Javier Moreno, ${ }^{3}$ Piedad S. Murdoch, ${ }^{4}$ \\ Miguel A. Rodríguez-Carvajal, ${ }^{2}$ Dulce N. Rodríguez-Navarro, ${ }^{5}$ José E. Ruiz-Sainz, ${ }^{1}$ \\ Juan Sanjuán, ${ }^{6}$ María J. Soto, ${ }^{6}$ and José M. Vinardell ${ }^{1}$ \\ ${ }^{1}$ Departamento de Microbiología, Facultad de Biología, Universidad de Sevilla, Avda. Reina Mercedes 6, C.P. 41012, Sevilla, \\ Spain; ${ }^{2}$ Departamento de Química Orgánica, Facultad de Química, Universidad de Sevilla, Apdo. 553, 41071-Sevilla, Spain; \\ ${ }^{3}$ Departamento de Biología Celular y Bioquímica Vegetal and ${ }^{4}$ Departamento de Biología Molecular, Facultad de Biología, \\ Universidad de Sevilla; ${ }^{5}$ IFAPA, Centro Las Torres-Tomejil. Apartado Oficial 41200, Alcalá del Río, Sevilla, Spain; \\ ${ }^{6}$ Departamento de Microbiología del Suelo y Sistemas Simbióticos, Estación Experimental del Zaidín, CSIC, Apartado 419, \\ 18080 Granada, Spain
}

Submitted 3 October 2011. Accepted 26 February 2012.

The Sinorhizobium fredii HH103 rkp-3 region has been isolated and sequenced. Based on the similarities between the S. fredii $\mathrm{HH103}$ rkpL, rkpM, rkpN, rkpO, rkpP, and rkpQ genes and their corresponding orthologues in Helicobacter pylori, we propose a possible pathway for the biosynthesis of the $S$. fredii $\mathrm{HH} 103 \mathrm{~K}$-antigen polysaccharide (KPS) repeating unit. Three $r k p-3$ genes ( $r k p M, r k p P$, and $r k p Q)$ involved in the biosynthesis of the HH103 KPS repeating unit (a derivative of the pseudaminic acid) have been mutated and analyzed. All the $r k p-3$ mutants failed to produce KPS and their lipopolysaccharide (LPS) profiles were altered. These mutants showed reduced motility and auto-agglutinated when early-stationary cultures were further incubated under static conditions. Glycine max, Vigna unguiculata (determinate nodule-forming legumes), and Cajanus cajan (indeterminate nodules) plants inoculated with mutants in rkpM, rkpQ, or rkpP only formed pseudonodules that did not fix nitrogen and were devoid of bacteria. In contrast, another indeterminate nodule-forming legume, Glycyrrhiza uralensis, was still able to form some nitrogen-fixing nodules with the three $S$. fredii $\mathrm{HH103}$ rifampicin-resistant $r k p-3$ mutants tested. Our results suggest that the severe symbiotic impairment of the $S$. fredii $r k p-3$ mutants with soybean, $V$. unguiculata, and $C$. cajan is mainly due to the LPS alterations rather than to the incapacity to produce KPS.

Rhizobia are soil bacteria able to establish symbiotic interactions with leguminous plants that lead to the formation of root nodules in which these bacteria fix atmospheric nitrogen. This Rhizobium-legume interaction involves a complex set of

Amino acid and nucleotide sequence data is available in the EMBL database under accession numbers JN642175 and JN642176.

Corresponding author: J. E. Ruiz-Sainz: Telephone: +34-954557121; Fax: +34-954557830; E-mail: rsainz@us.es

* The $\boldsymbol{e}$-Xtra logo stands for "electronic extra" and indicates that Figure 5 appears in color online. molecular interactions that takes place during the development and maintenance of nitrogen-fixing nodules on the plant roots. Inside the nodules, rhizobia fix atmospheric nitrogen that becomes an assimilable source of nitrogen to the plant. This molecular dialogue between the bacteria and the plant begins when flavonoids, naturally exuded by the legume, activate the transcription of bacterial nodulation genes. Some of these genes (nod, nol, and noe) encode proteins responsible for the biosynthesis and secretion of signal molecules called "Nod factors" or lipochitin oligosaccharides, which mediate species specificity and induce the development of root nodules in the plant (Gage 2004; Jones et al. 2007).

In addition to Nod factors, different rhizobial surface polysaccharides are commonly necessary for successful nodulation. Exopolysaccharides (EPS), lipopolysaccharides (LPS), capsular polysaccharides (KPS [K-antigen polysaccharides]), and cyclic glucans (CG) are the main rhizobial polysaccharides investigated, because they might act as signal molecules or could prevent plant defense reactions (Breedveld and Miller 1998; Fraysse et al. 2003; Krol and Becker 2009; Mithöfer 2002). KPS and CG but not EPS appear to play important roles in the S. fredii-soybean symbiosis (Crespo-Rivas et al. 2009; Parada et al. 2006). The symbiotic properties of $S$. fredii mutants specifically affected in genes responsible for the biosynthesis of LPS have not been reported. In Bradyrhizobium japonicum, however, mutants showing deficiencies in structure of their LPS are symbiotically impaired (Puvanesarajah et al. 1987; Quelas et al. 2010).

$S$. fredii possesses an exceptionally broad host range (Pueppke and Broughton 1999), so that this rhizobial species is especially interesting for the study of the relevance of each bacterial surface polysaccharide in the symbiotic interaction with many different legumes, including both plants forming determinate or indeterminate nodules. In the S. melilotialfalfa symbiosis, which generates the formation of indeterminate nodules, KPS can substitute for EPS in the nodulation process (Reuhs et al. 1995). In contrast, KPS by itself appears to be relevant in the $S$. fredii-soybean symbiosis, which induces the formation of determinate nodules. In this symbi- 
osis, EPS cannot substitute for the KPS function (Parada et al. 2006).

Three $r k p$ gene clusters ( $r k p-1, r k p-2$, and $r k p-3)$ involved in KPS production were identified in $S$. meliloti Rm41 (Kereszt et al. 1998; Kiss et al. 2001; Putnoky et al. 1990). This strain produced a $\mathrm{K}$ antigen of strain-specific structure, designated as the $\mathrm{K}_{\mathrm{R}} 5$ antigen (Kiss et al. 2001). In S. meliloti AK631 (an exoB mutant derivative of $S$. meliloti $\mathrm{Rm} 41$ ), the repeating unit of the $K_{R} 5$ antigen produced is composed of a hexose and a derivative of the pseudaminic acid (PseAc) (Kannenberg et al. 1998). It has also been shown that membrane-anchored 3-deoxy-D-manno-2-octulosonic acid (Kdo) homopolymers (polyKdo) are consensus sinorhizobial capsular polysaccharides present in S. meliloti Rm41, S. meliloti Rm1021, and S. fredii HH103 (Chataigné et al. 2008; Krol and Becker 2009). In $S$. meliloti Rm1021, this polyKdo is symbiotically inactive (Fraysse et al. 2005; Reuhs et al. 1995).

Most of the $S$. meliloti Rm41 rkp mutants are unable to produce wild-type KPS ( $\mathrm{K}_{\mathrm{R}} 5$ antigen) and do not infect alfalfa nodule cells. The $r k p A$ to $r k p F$ genes of the $r k p-1$ region show significant sequence similarity to type I fatty acid synthases (Becker et al. 2005; Geiger and López-Lara, 2002; Petrovics et al. 1993), so that they are most probably involved in the synthesis of a specific lipid carrier for KPS biosynthesis. The $r k p-2$ region comprises two genes, lps $L$ and $r k p K$. The former is required for wild-type LPS biosynthesis, while the latter appears necessary for the production of wild-type LPS and KPS (Kereszt et al. 1998). The $r k p-3$ region contains the $r k p L, r k p M, r k p N$, $r k p O, r k p P$, and $r k p Q$ gene cluster, which appears to be involved in the synthesis of the PseAc component of the KPS produced by $S$. meliloti $\mathrm{Rm} 41$ (Kiss et al. 2001). Mutations in the $S$. meliloti AK631 rkpL, rkpM, rkpN, rkpO, rkpP, and rkpQ genes abolish $\mathrm{K}_{\mathrm{R}} 5$ antigen production and impair the bacterial symbiotic capacity with Medicago sativa (Kiss et al. 2001). The in silico $S$. meliloti Rm41 RkpLMNOPQ predicted proteins show homology to the respective putative products of the Campylobacter jejuni and Helicobacter pylori pseBCFGHI genes, which are involved in the biosynthesis of PseAc (Guerry et al. 2006; Schirm et al. 2003; Schoenhofen et al. 2006).

Rhizobium sp. strain NGR234 is a broad host range endosymbiont able to form nitrogen-fixing symbioses with more than 112 genera of legumes (Pueppke and Broughton 1999). Although NGR234 and $S$. fredii HH103 share the capacity to nodulate many particular legumes, the former is not able to nodulate soybean. The structure of the KPS produced by Rhizobium sp. strain NGR234 also contains PseAc and is very similar to that of the $\mathrm{K}_{\mathrm{R}} 5$ antigen of $S$. meliloti $\mathrm{Rm} 41$. A deletion of the $r k p M, r k p N$, and part of $r k p O$ generated a NGR234 mutant that does not produce the $\mathrm{K}$-antigen and showed reduced nodulation efficiency on different legumes, such as Vigna unguiculata (Le Quéré et al. 2006).

S. fredii HH103 constitutively produces two types of KPS. One of them, here called poly-PseAc, is a homopolymer of a derivative of the pseudaminic-acid (Gil-Serrano et al. 1999), while the other is a homopolymer of Kdo (Chataigné et al. 2008). The implication of the $S$. fredii $\mathrm{HH} 103$ poly-Kdo in the bacterial symbiotic capacity has not been investigated, but the symbiotic relevance of the $S$. fredii $\mathrm{HH} 103$ poly-PseAc appears to be related to each specific bacterium-legume interaction rather than to the type of nodule, determinate or indeterminate, formed by the host plant. The poly-PseAc (hereafter called "KPS") plays a relevant role in the $S$. fredii-soybean symbiosis, since mutants affected in genes of the $r k p-1$ region are symbiotically impaired with soybean (Hidalgo et al. 2010; Margaret-Oliver et al. 2012; Parada et al. 2006). However, the $S$. fredii HH103 rkp mutants analyzed so far are not impaired for nodulation of cowpea, another determinate-nodule-forming legume (Hidalgo et al. 2010). Instead, S. fredii HH103 rkp-1 mutants are negatively affected to nodulate Glycyrrhiza uralensis, an indeterminate nodule-forming legume (MargaretOliver et al. 2012). Glycyrrhiza uralensis is one of the 50 fundamental herbs used in traditional Chinese medicine and can be used for many different healing purposes, such as stress relief or in asthma and respiratory illnesses.

In this study, we identified and characterized genes of the $r k p-3$ locus that appear to be involved in the synthesis of the repeating unit (poly-PseAc) of the $S$. fredii HH103 KPS. We showed that mutations in the $\operatorname{rkpM}, \operatorname{rkp} Q$, and $r k p P$ genes not only abolish poly-PseAc KPS production but also alter the bacterial LPS. These mutants showed reduced mobility, autoagglutinated in tryptone yeast (TY) liquid medium, and failed to form nitrogen-fixing nodules with Glycine max, Vigna unguiculata (two determinate nodule-forming legumes), and $\mathrm{Ca}$ janus cajan (indeterminate nodules). In contrast, they were still able to form nitrogen-fixing nodules with Glycyrrhiza uralensis, another indeterminate nodule-forming legume, also called Chinese liquorice. We also propose a possible pathway for the biosynthesis of the $S$. fredii HH103 KPS repeating unit.

Table 1. Primers used in polymerase chain reaction (PCR) experiments

\begin{tabular}{|c|c|c|c|}
\hline Primer & Sequence $\left(5^{\prime}-3^{\prime}\right)^{\mathrm{a}}$ & Position of priming site & Predicted length of PCR product $^{b}$ \\
\hline SmrkpL-F & GAACGCATGACTCGCTTCATGA & $r k p L$ coding region (from $\mathrm{Rm} 41$ ) & 1,426-bp in Sinorhizobium meliloti $\mathrm{Rm} 41$ \\
\hline SmrkpM-R & GTATGAACCGGAATATAGTGCA & & \\
\hline $\begin{array}{l}\mathrm{HH} r k p L-\mathrm{F} \\
\mathrm{HH} r k p M-\mathrm{R} 1\end{array}$ & $\begin{array}{l}\text { AGCTAGTGTGGCACGCCTTTGA } \\
\text { TCGAAATCCCGCCGCGCGATTT }\end{array}$ & $\begin{array}{l}r k p L \text { coding region } \\
r k p M \text { coding region }\end{array}$ & 1,326-bp in $S$. fredii $\mathrm{HH} 103$. \\
\hline $\begin{array}{l}\mathrm{HH} r k p M-\mathrm{F} \\
\mathrm{HH} r k p M-\mathrm{R} 2\end{array}$ & $\begin{array}{l}\text { CCGGCGGAACTTGAACGCAA } \\
\text { AGGCTGCGTGTGAACCGGAA }\end{array}$ & $r k p M$ coding region & $\begin{array}{l}690 \mathrm{bp} \text { in } S . \text { fredii } \mathrm{HH} 103 \mathrm{Rif}^{\mathrm{r}} \text { and } 2,726 \mathrm{bp} \\
\text { in SVQ581 }\end{array}$ \\
\hline lacZint-R & GCCTCTTCGCTATTACGCCA & lac $Z$ coding region & $\begin{array}{l}\text { Estimated about } 550 \text { bp in SVQ582 (by using } \\
\text { HHrkpM-F and lacZint-R) }\end{array}$ \\
\hline $\begin{array}{l}\mathrm{HH} r k p Q \mathrm{~F} 1 \\
\mathrm{HH} r k p Q \mathrm{R} 1\end{array}$ & $\begin{array}{l}\text { CGACGGGACGTTCTACGACA } \\
\text { TCTCGATCAACGAGCCCCCTA }\end{array}$ & $r k p Q$ coding region & $\begin{array}{l}816 \mathrm{bp} \text { in HH103 } \mathrm{Rif}^{\mathrm{r}}, 2,852 \mathrm{bp} \text { in SVQ592, } \\
\text { and estimated about } 590 \text { bp in SVQ594 (by } \\
\text { using HHrkpQF1 and lacZint-R) }\end{array}$ \\
\hline $\begin{array}{l}\text { HHrkpPext-F } \\
\text { HHrkpPext-R }\end{array}$ & $\begin{array}{l}\text { GGAAGAGGATCCTGATGTCGA } \\
\text { TATAGCGGATCCCCGCCCAA }\end{array}$ & $\begin{array}{l}r k p M \text { coding region } \\
r k p Q \text { coding region }\end{array}$ & 1,180 bp in HH103 Rif $^{r}$ \\
\hline
\end{tabular}

${ }^{a}$ The underlined sequence (GGATCC) in primers HHrkpPext-F and HHrkpPext-R is the nucleotide sequence recognized by the endonuclease BamHI. This BamHI restriction site, which is not present in the original rhizobial sequences, has been created for cloning purposes. The original sequences are CCA CCG (for HHrkpPext-F) and GTCTTT (for HHrkpPext-R).

${ }^{\mathrm{b}}$ The pair of primers $r k p M$-F and $r k p M$-R2 was used to check the insertion of the $\Omega$ interposon in SVQ581. Primers $r k p M$ F and lacZint-R were used to check the insertion of the lacZ $\mathrm{p}-\mathrm{Gm}^{\mathrm{r}}$ cassette in SVQ582. Primers $r k p Q \mathrm{~F} 1$ and $r k p Q \mathrm{R} 1$ were used to check the insertion of the $\Omega$ interposon in SVQ592. Primers $r k p Q F 1$ and lacZint-R were used to check the insertion of the lacZ $\Delta \mathrm{p}-\mathrm{Gm}^{\mathrm{r}}$ cassette in SVQ594. 


\section{RESULTS}

Isolation of the $r k p L, r k p M, r k p N, r k p O, r k p P$, and $r k p Q$ genes of $S$. fredii $\mathrm{HH} 103$.

To isolate genes of the $S$. fredii $\mathrm{HH} 103$ rkp-3 region, primers $\mathrm{Sm} r k p L-\mathrm{F}$ and $\mathrm{Sm} r k p M$-R were respectively designed from the coding sequences of the $r k p L$ and $r k p M$ genes of $S$. meliloti Rm41 (Table 1). Using S. fredii HH103 genomic DNA as a template, primers SmrkpL-F and SmrkpM-R led to the polymerase chain reaction (PCR) amplification of a $1.3-\mathrm{kb}$ fragment that showed $80 \%$ identity with the $3^{\prime}$ end of $r k p L$ and the $5^{\prime}$ end of rkpM of $S$. meliloti $\mathrm{Rm} 41$. This fragment was sequenced, and primers $\mathrm{HH} r k p L-\mathrm{F}$ and $\mathrm{HH} r k p M$-R1, respectively, were designed from the $S$. fredii $\mathrm{HH} 103$ rkpL and $r k p M$ coding sequences (Table 1). Then, 1,200 clones of a genomic library of $S$. fredii HH103 were screened for positive PCR amplification with primers $\mathrm{HH} r k p L-\mathrm{F}$ and $\mathrm{HH} r k p M$-R1, resulting in the identification of cosmid pMUS664. DNA sequencing of an 11,274-bp fragment (accession number JN642175) demonstrated the presence of seven open reading frames (ORF) showing the same polarity (Fig. 1). The G+C content of this DNA fragment was $54.4 \%$. Six ORF encode for putative proteins that have a 68 to $93 \%$ identity (Table 2) with their respective orthologues (rkpL, rkpM, rkpN, rkpO, rkpP, and rkpQ) of $S$. meliloti $\mathrm{Rm} 41$. Five of these $S$. fredii $\mathrm{HH} 103$ putative proteins, RkpLMNOQ, have a 74 to $95 \%$ and a 38 to $67 \%$ identity with the corresponding orthologues of Rhizobium sp. strain NGR234 and Aeromonas caviae, respectively.
A large ORF of 4,089-bp, coding for a putative protein of 1,362 amino acids (aa), is located close to the $5^{\prime}$ end of $r k p L$. The deduced protein, provisionally annotated as SfHH103 b1955 in the $S$. fredii HH103 genome sequence project (Margaret et al. 2011), has two regions that show homology to other bacterial hypothetical proteins in computer (Blast) analyses. The amino terminus of SfHH103_b1955 (442 residues) is homologous (55\% identity) to the entire S. meliloti $\mathrm{Rm} 1021$ RkpZ protein (440 residues), while its carboxyl-terminus (from residues 831 to 1361 ) shows homology (31\% identity) with a hypothetical protein (of 1,043 residues) of Roseobacter sp. strain SK209-2-6. The central part of SfHH103_b1955 (from residues 443 to 851 ) does not show significant homology in Blast analyses.

Two ORF (provisionally annotated as SfHH103_b1962 and SfHH103_b1963) appear in the vicinity of the $3^{\prime}$ end of $r k p Q$. They are transcribed in the opposite direction to $r k p Q$ and coded for putative transposases. SfHH103_b1963 and SfHH103_ b1962 code for putative transposases (of 166 and 140 aa) that are respectively homologous to transposases of the insertion sequences NGRIS-2b (93\% identity in 166 aa) and NGRIS-2a (92\% identity in 140 aa) of Rhizobium sp. strain NGR234. SfHH103_b1962 also showed 98\% identity with 419 bp of the $5^{\prime}$ end of the 1,248-bp repetitive sequence RFRS9 (U18764.1) of Sinorhizobium fredii USDA257 (Krishnan and Pueppke 1993).

The complete genome sequence project of $S$. fredii $\mathrm{HH} 103$ (Margaret et al. 2011) has shown the presence of three ORF homologous to the $S$. meliloti $\mathrm{Rm} 41$ and Rhizobium sp. strain
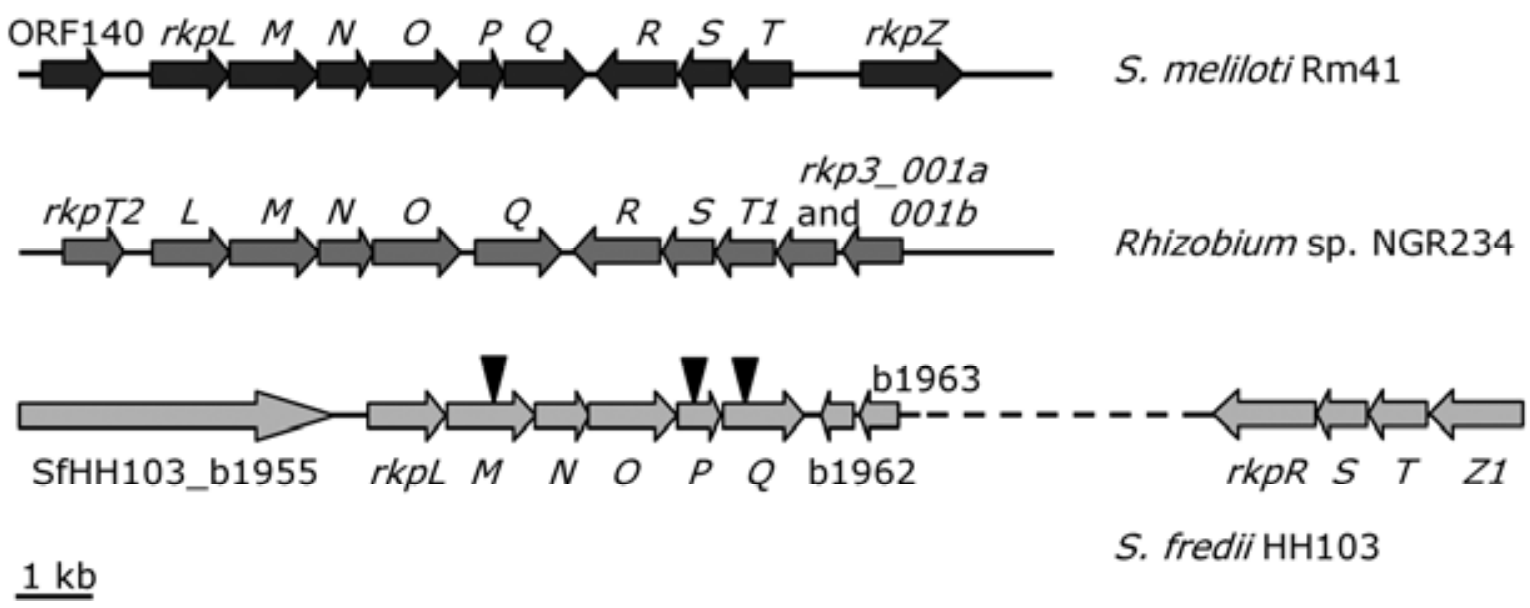

S. fredii $\mathrm{HH} 103$

Fig. 1. Genetic organization of the rkp-3 region of Sinorhizobium fredii HH103 and a comparison to that of S. meliloti Rm41 and Rhizobium sp. strain NGR234.

Table 2. Proteins encoded by the Sinorhizobium fredii HH103 rkp-3 region and identities with the corresponding proteins of S. meliloti Rm41 and Rhizobium sp. strain NGR $234^{\mathrm{a}}$

\begin{tabular}{|c|c|c|c|c|}
\hline \multirow[b]{2}{*}{ Protein } & \multirow[b]{2}{*}{ Orthologue $^{\text {b }}$} & \multirow[b]{2}{*}{ Putative function $^{c}$} & \multicolumn{2}{|r|}{ Identity with } \\
\hline & & & S. meliloti Rm41 (\%) & Rhizobium sp. strain NGR234 (\%) \\
\hline RkpL (334) & PseB & NAD(p)-dependent dehydratase/epimerase & 93 RkpL (334) & 95 RkpL (334) \\
\hline RkpM (386) & PseC & Pyridoxal phosphate (PLP)-dependent aminotransferase & 87 RkpM (386) & 86 RkpM (386) \\
\hline RkpN (234) & PseF & CMP-pseudaminic acid synthase & 80 RkpN (227) & 84 RkpN (377) \\
\hline RkpO (382) & PseG & Nucleotidase & 68 RkpO (377) & 74 RkpO (377) \\
\hline RkpP (184) & PseH & $\mathrm{N}$-acetyltransferase & 80 RkpP (185) & Not present \\
\hline RkpQ (350) & PseI & Pseudaminic acid synthase & 90 RkpQ (354) & 89 RkpQ (350) \\
\hline RkpR (446) & Not present & Polysaccharide export protein & $89 \mathrm{RkpR} / \mathrm{KpsE}(317)$ & 85 RkpR (443) \\
\hline RkpS (219) & Not present & Polysaccharide export protein & $91 \mathrm{RkpS}(219)$ & 92 RkpS (219) \\
\hline RkpT (256) & Not present & Cell surface polysaccharide export ABC-2 transporter & 91 RkpT1 (259) & 91 RkpT1 (256) \\
\hline RkpZ (406) & Not present & Capsule polysaccharide biosynthesis protein & 65 RkpZ1 (432) & $\begin{array}{l}\text { Two open reading frames } \\
\text { (Rkp3_001a and Rkp3_001b) }\end{array}$ \\
\hline
\end{tabular}

\footnotetext{
${ }^{a}$ Number of residues of each protein is shown in parentheses.

${ }^{\mathrm{b}}$ Corresponding orthologue of Helicobacter pylori and Campylobacter jejuni.

${ }^{\mathrm{c}}$ Proposed function as defined in S. meliloti Rm41 (Kiss et al. 2001) and H. pylori and Campylobacter jejuni (Schoenhofen et al. 2006).
} 
NGR234 rkpT, rkpS, and rkpR genes (Fig. 1; accession number JN642176). These three genes are putatively involved in polysaccharide export (Kiss et al. 2001). In Rm41 and NGR234 strains, the $r k p T, r k p S$, and $r k p R$ genes are in the vicinity of the $\operatorname{rkp} Q$ gene and are transcribed in the opposite direction. In contrast, the $S$. fredii $\mathrm{HH} 103$ rkpT, rkpS, and $r k p R$ genes, together with a gene ( $r k p Z)$ coding for a KPS chain-length determination enzyme, are located approximately $7 \mathrm{~kb}$ downstream of $r k p Q$ in the 2.1-Mbp plasmid (Margaret et al. 2011; unpublished data).

\section{S. fredii HH103 mutants affected} in the $r k p M, r k p P$, or $r k p Q$ genes do not produce KPS and show an altered electrophoretic LPS pattern.

As described below, $S$. fredii $\mathrm{HH} 103$ rkpM and $r k p Q$ mutant derivatives carrying the Omega interposon were constructed and were named SVQ581 and SVQ592, respectively. S. fredii $\mathrm{HH} 103$ rkpM, rkpP, and $r k p Q$ mutants carrying the $l a c Z \Delta \mathrm{p}-$ $\mathrm{Gm}^{\mathrm{r}}$ cassette were also constructed and were named SVQ582, SVQ667, and SVQ594, respectively.

HH103 mutants $r k p M:: \Omega$, rkpM::lacZ, rkpP::lacZ, rkp $Q:: \Omega$, and $\operatorname{rkp} Q:: l a c Z$ were investigated for the production of KPS by polyacrylamide gel electrophoresis (PAGE) followed by a treatment with Alcian Blue and silver staining. PAGE experiments to visualize KPS were carried out in the absence of sodium dodecyl sulfate (SDS) to avoid interferences of LPS. The silverstained material that presumably corresponds to the high-molecular weight forms of KPS was not present in crude cell extracts of mutants $\operatorname{rkpM}:: \Omega, \operatorname{rkp} M:: l a c Z, \operatorname{rkp} Q:: \Omega, \operatorname{rkp} Q:: l a c Z$, and $\operatorname{rkpP}:$ :lacZ (Fig. 2, lanes 2, 4, 7, 8, and 11, respectively). The wild-type KPS produced by the parental strain HH103 Rif $^{\text {r }}$ (rifampicin resistant) (Fig. 3; Gil-Serrano et al. 1999) was not detected by ${ }^{1} \mathrm{H}-\mathrm{NMR}$ (nuclear magnetic resonance) analyses in the $r k p M, r k p P$, and $r k p Q$ mutants investigated, supporting the hypothesis that the $r k p M, r k p O$, and $r k p P$ genes are required for KPS production in $S$. fredii $\mathrm{HH} 103 .{ }^{1} \mathrm{H}-\mathrm{NMR}$ spectra of the HH103 rkpM:: $\Omega$ and $\operatorname{rkp} Q:: \Omega$ derivatives carrying cosmid pMUS664 showed the presence of the wild-type KPS. As expected, CG production was not affected in any of the $r k p-3$ mutants analyzed in this study.
In Aeromonas spp., the inactivation of the $r k p-3$ orthologous genes has been described to affect both LPS production and motility (Tabei et al. 2009). The LPS profiles of the rkpM, $r k p Q$, and $r k p P$ mutants were analyzed by PAGE experiments performed in the presence of SDS (Fig. 4) as well as by immunostaining experiments using a monoclonal antibody (NB6228.22) that recognizes the LPS of HH103 (Buendía-Clavería

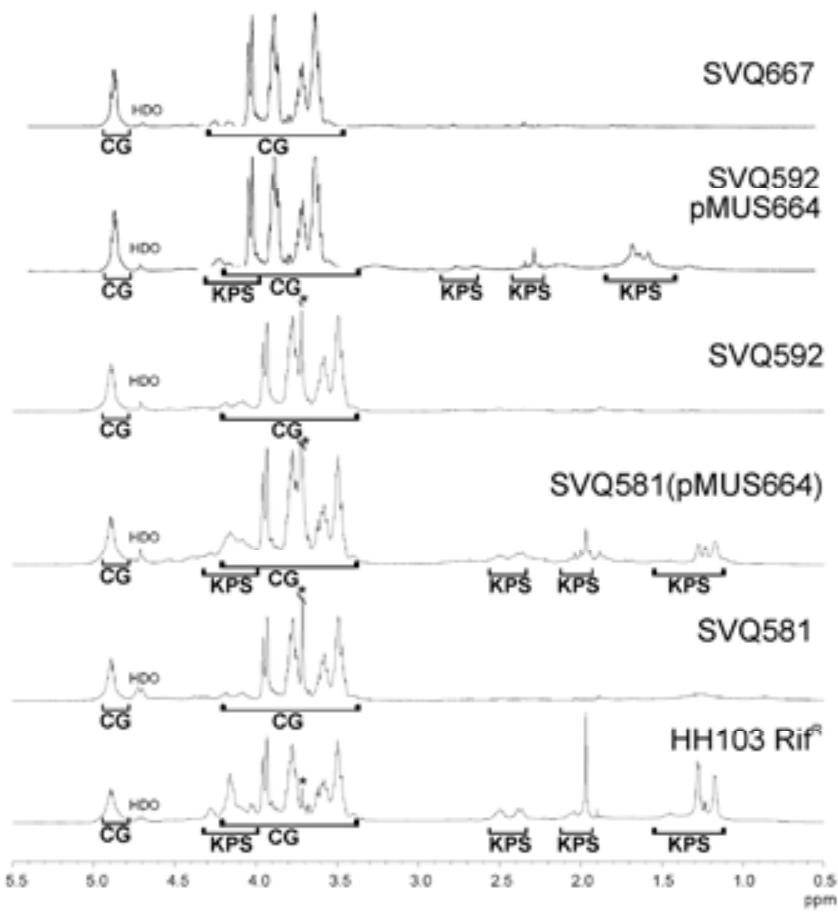

Fig. 3. Nuclear magnetic resonance (NMR) analysis of K-antigen polysaccharide (KPS) production by Sinorhizobium fredii strains. ${ }^{1} \mathrm{H}-\mathrm{NMR}$ spectra $(500 \mathrm{MHz})$ of crude cell extracts containing surface polysaccharides

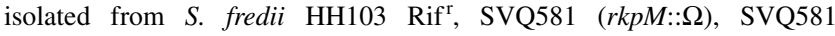

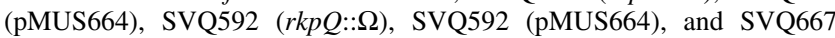
( $\left.r k p P:: l a c Z \Delta \mathrm{p}-\mathrm{Gm}^{\mathrm{r}}\right)$. Signals corresponding to KPS, cyclic glucans (CG), or the solvent (HDO, deuterated water) are indicated.

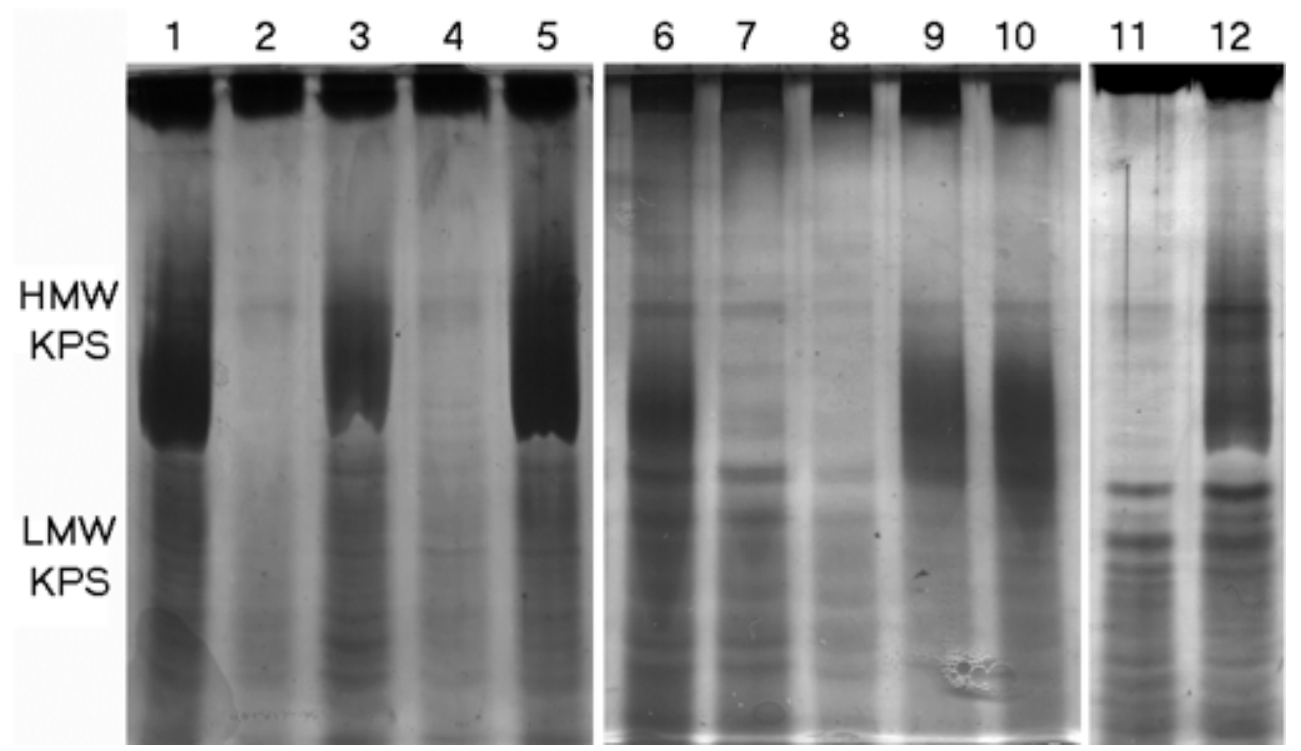

Fig. 2. Polyacrylamide gel electrophoresis analysis of K-antigen polysaccharide (KPS) production by Sinorhizobium fredii HH103 Rif ${ }^{\mathrm{r}}$ and different $r k p$ derivatives. Samples were run in the absence of detergent (SDS), were treated with Alcian Blue, and were silver stained. Lanes 1, 5, 6, and 12, HH103 Rif ${ }^{\text {r. }}$

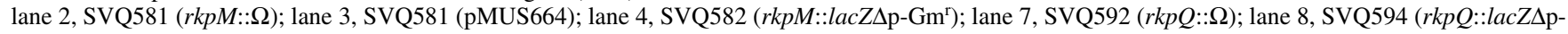

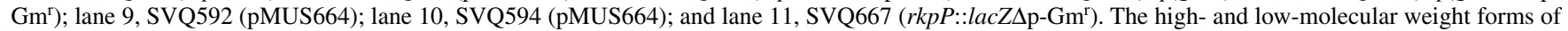
KPS are indicated as HMW-KPS and LMW-KPS, respectively. 
et al. 2003). The electrophoretic profile of mutants $r k p M:: \Omega$,

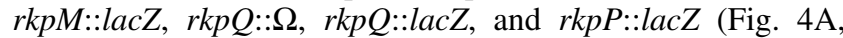
lanes $2,4,6,8$, and 10 , respectively) was altered in comparison with that of HH103 Rif $^{\mathrm{r}}$ (Fig. 4A, lanes 1, 5, 9, and 12).
These altered profiles consisted of an increase in the electrophoretic mobility of both the smooth (slow-migrating bands) and the rough (fast-migrating bands) LPS. The introduction of cosmid pMUS664 in mutants SVQ581, SVQ592, and SVQ667

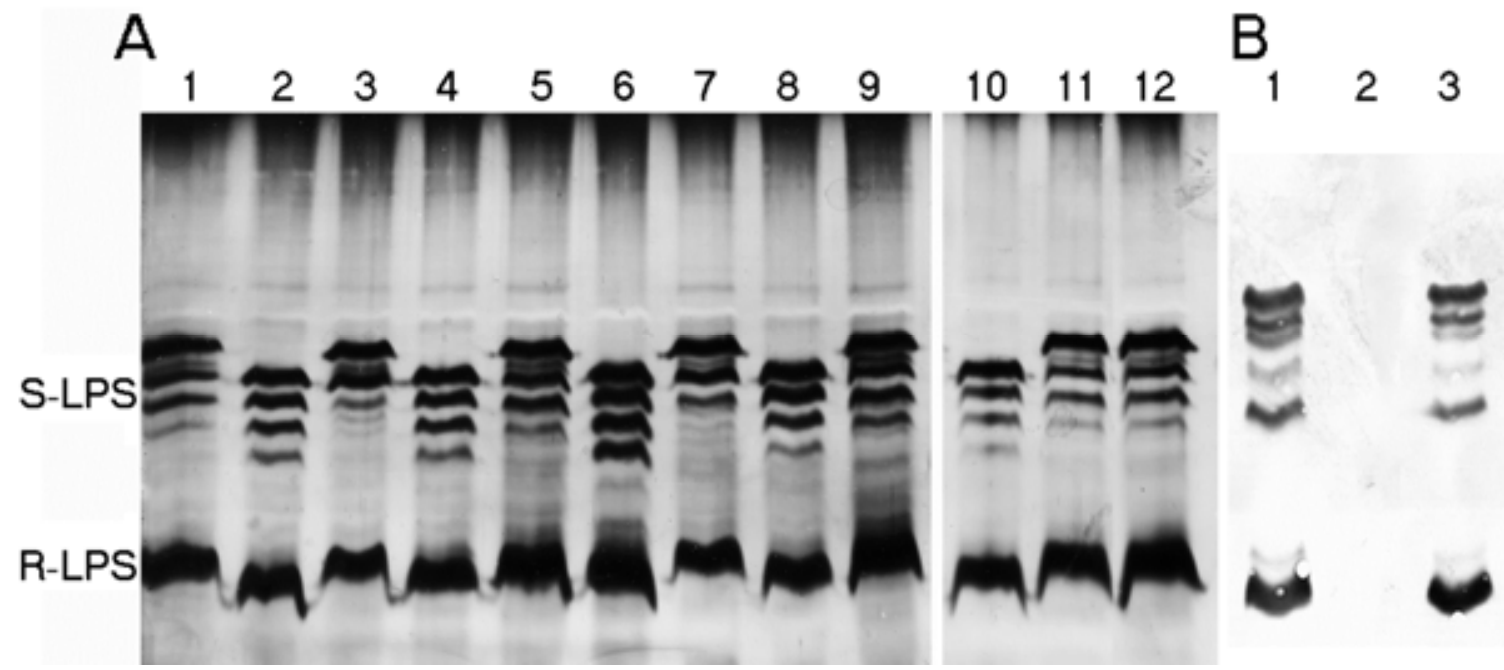

Fig. 4. A, Sodium dodecyl sulfate-polyacrylamide gel electrophoresis and silver-staining or B, immuno-staining using the monoclonal antibody NB6-228.22 of lipopolysaccharides (LPS) crude extracts from Sinorhizobium fredii HH103 Rif $^{\mathrm{r}}$ and its $r k p M:: \Omega$ (SVQ581), rkpM::lacZLp-Gm ${ }^{\mathrm{r}}(\mathrm{SVQ} 582), r k p P:: l^{2}$ acZ-Gm ${ }^{\mathrm{r}}$ (SVQ667), $r k p Q:: \Omega$ (SVQ592), and $r k p Q:: l a c Z \Delta \mathrm{p}-\mathrm{Gm}^{\mathrm{r}}$ (SVQ594) mutant derivatives. The rough and smooth forms of LPS are indicated as R-LPS and S-LPS, respectively. A, lanes 1, 5, 9, and 12, HH103 Rif ${ }^{\mathrm{r}}$; lane 2, SVQ581; lane 3, SVQ581 (pMUS664); lane 4, SVQ582; lane 6, SVQ592; lane 7, SVQ592 (pMUS664); lane 8, SVQ594; lane 10, SVQ667; and lane 11, SVQ667 (pMUS664). B, lane 1, HH103 Rif ${ }^{\mathrm{r}}$; lane 2, SVQ581; and lane 3, SVQ581 (pMUS664).

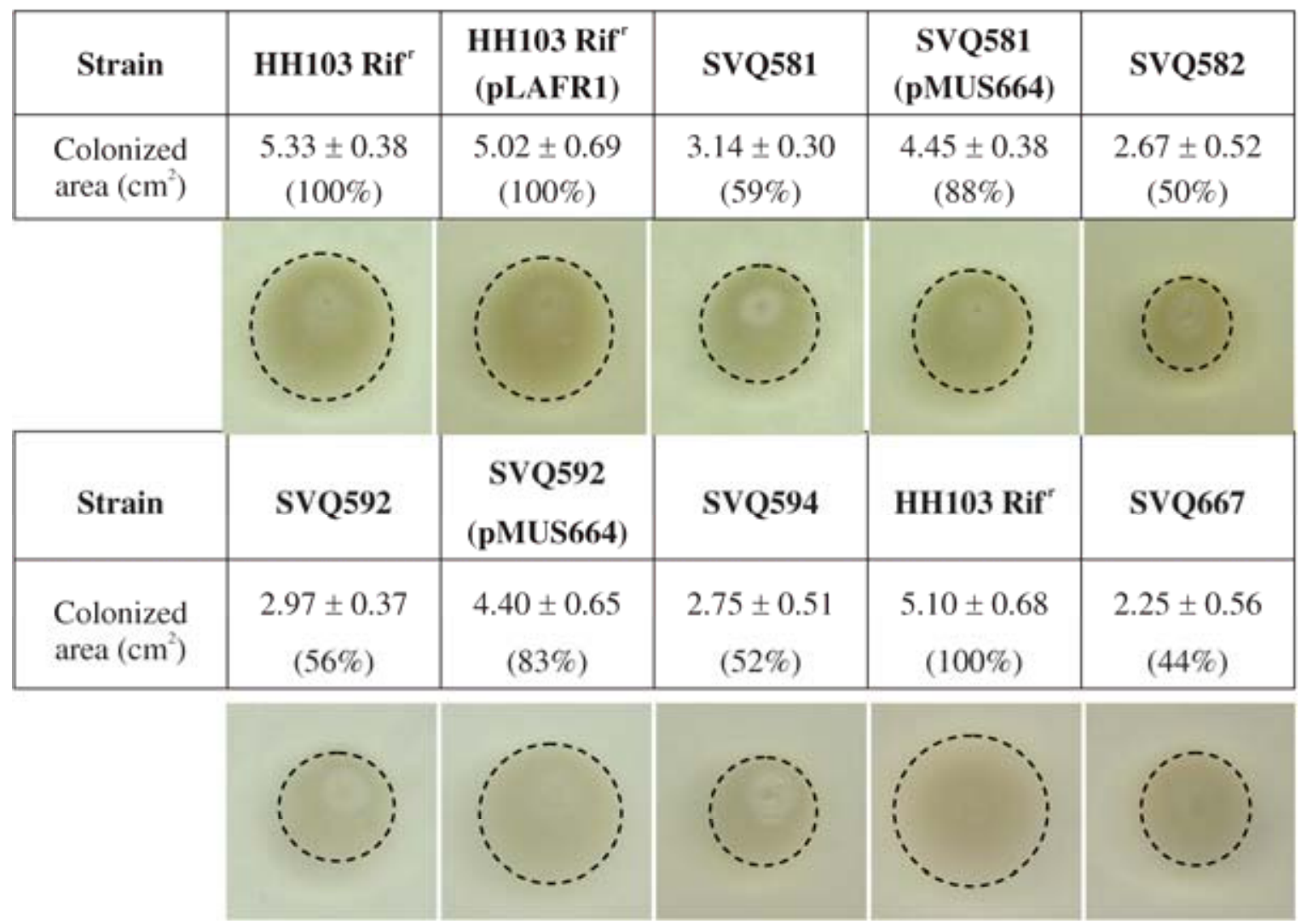

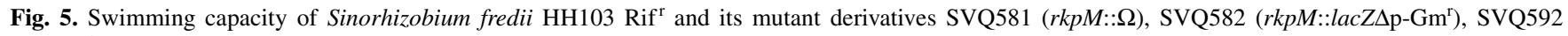
$(r k p Q:: \Omega)$, SVQ594 $\left(r k p Q:: l a c Z \Delta \mathrm{p}-\mathrm{Gm}^{\mathrm{r}}\right)$, and SVQ667 $\left(r k p P:: l a c Z \Delta \mathrm{p}-\mathrm{Gm}^{\mathrm{r}}\right)$. Data represent averages of eight replicates. Numbers in brackets are percentages of the area colonized by 3-day-old SVQ81, SVQ582, SVQ592, SVQ594, and SVQ667 cultures in relation to that occupied by the wild-type strain HH103 Rif ${ }^{r}$. The percentage of the area colonized by SVQ581 (pMUS664) and SVQ592 (pMUS664) was calculated in relation to that of HH103 Rif ${ }^{r}$ (pLAFR1). The dotted circles indicate the approximated limits of the bacterial growth. The area colonized by each mutant was pairwise compared with that of the parental strain HH103 Rif ${ }^{\mathrm{r}}$ (or with HH103 Rif $^{\mathrm{r}}$ [pLAFR1] if mutants were carrying cosmid pMUS664) by using the Mann-Whitney nonparametrical test. The areas colonized by mutants SVQ581, SVQ582, SVQ592, SVQ594, and SVQ667 were significantly different $(P<0.01)$ at the level $\alpha=5 \%$. Significant differences (at $\alpha=5 \%$ ) were not found among HH103 Rif $^{\mathrm{r}}$ (pLAFR1), SVQ581 (pMUS664), and SVQ592 (pMUS664) cultures. 
(Fig. 4A, lanes 3, 7, and 11, respectively) restored the wildtype electrophoretic pattern. These results show that the inactivation of the $r k p M, r k p Q$, or $r k p P$ genes has an effect not only on KPS but also on LPS production. The monoclonal antibody NB6-228.22 recognizes the $S$. fredii $\mathrm{HH} 103$ Rif $^{\mathrm{r}}$ LPS (Fig. 4B, lane 1) but failed in the recognition of the altered LPS produced by mutants SVQ581 (Fig. 4B, lane 2), SVQ592 (not shown), and SVQ667 (not shown). The antibody, however, recognized the LPS produced by mutants SVQ581, SVQ592, and SVQ667 carrying cosmid pMUS664 (Fig. 4B, lane 3, and data not shown).

Inactivation of the $S$. fredii $\mathrm{HH103}$ rkpM, rkpP, or $r k p Q$ genes affected the bacterial motility and auto-agglutination.

Mutants affected in rkpM (SVQ581 and SVQ582), rkpQ (SVQ592 and SVQ594), and rkpP (SVQ667) were also investigated for their swimming capacity. Figure 5 shows that the motility of all the mutants tested (expressed as the surface area colonized by the bacteria after three days of incubation) was significantly lower in comparison with that of HH103 Rif ${ }^{\mathrm{r}}$. The introduction of cosmid pMUS664 in mutants SVQ581 and

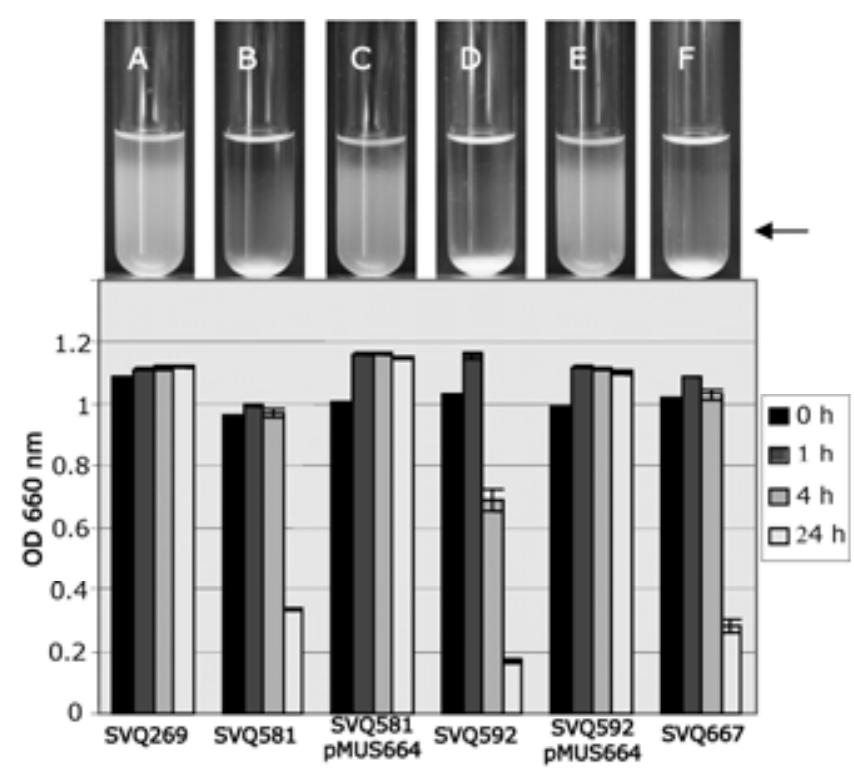

Fig. 6. Auto-agglutination assays of Sinorhizobium fredii $\mathrm{HH} 103 \mathrm{Rif}^{\mathrm{r}}$ and its

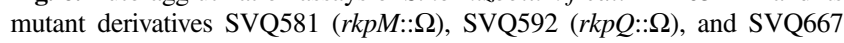
( $\left.r k p P:: l a c Z \Delta \mathrm{p}-\mathrm{Gm}^{\mathrm{r}}\right)$. Tubes 1 to 7 show the aspect of liquid cultures after 24 $\mathrm{h}$ in static conditions. Tube 1, S. fredii HH103 Rif ${ }^{\mathrm{r}}$; tube 2, SVQ581; tube 3, SVQ581 (pMUS664); tube 4, SVQ592; tube 5, SVQ592 (pMUS664); tube 6, SVQ667; and tube 7, SVQ667 (pMUS664). The arrow indicates the depth in the liquid column at which the optical density was measured. The optical density of the cultures was monitored at 0 (black bar), 1 (dark-gray bar), 4 (light-gray bar), and 24 (white bar) h of incubation at static conditions.
SVQ592 increased their motility to values that were close to those scored for the wild-type strain carrying pLAFR1, the empty cosmid vector.

TY liquid cultures of HH103 Rif ${ }^{\mathrm{r}}$, SVQ582, SVQ594, and SVQ667 at their early stationary-growth phase (optical density at $600 \mathrm{~nm}\left[\mathrm{OD}_{600}\right]>1.0$ ) were left in static for $24 \mathrm{~h}$ to investigate whether the reduction in bacterial motility shown by the rkp mutants was also associated to an increase of the speed at which bacteria deposited at the bottom of the tube. The intensity of auto-agglutination of SVQ582, SVQ594, and SVQ667 cultures was clearly higher than that shown by the HH103 Rif ${ }^{\mathrm{r}}$ culture (Fig. 6). Introduction of cosmid pMUS664 into the three $r k p$ mutants reduced bacterial auto-agglutination at wildtype levels (Fig. 6; data not shown). Differences in auto-agglutination were not observed when bacteria were grown in liquid yeast extract mannitol (YMB) medium.

\section{Effect of pH, flavonoids, and YMB composition on the expression of rkpM.}

The flavonoid genistein can be found in soybean root exudates (Kosslak et al. 1987) and is able to activate the transcription of $S$. fredii $\mathrm{HH} 103$ nod genes (Vinardell et al. 2004a). S. fredii SVQ582 (which carry a rkpM::lacZ $\Delta \mathrm{p}-\mathrm{Gm}^{\mathrm{r}}$ fusion) cultures grown in the presence of and the absence of the flavonoid genistein were assayed for $\beta$-galactosidase activity. Three independent experiments, each composed of two replicates, showed that the LacZ activity of SVQ582 cultures in the presence of genistein $(287.8 \pm 56.8$ Miller units $)$ was similar to that in the absence of the flavonoid (291.5 \pm 41.7 Miller units).

The effect of the $\mathrm{pH}$ at which bacteria were grown on rkpM expression was investigated by culturing mutant SVQ582 in acidic-, neutral-, and alkaline-buffered YMB media ( $\mathrm{pH}$ 6.0, 7.0, and 8.0, respectively). Nonbuffered YMB media, with a $\mathrm{pH}$ value of 7.0 at the time of inoculation, was also included. Three independent experiments, each composed of two replicates, showed that the $\beta$-galactosidase activity of SVQ582 cultures was similar in all the conditions tested (data not shown).

The LacZ activity of SVQ582 cultures grown in different formulations of the YMB medium (in which the amounts of yeast extract and mannitol had been altered) was determined, to investigate the effect of $\mathrm{C}$ and $\mathrm{N}$ availability on the $r k p M$ expression. The higher and lower values of SVQ582 LacZ activity were found, respectively, in YMB formulations containing the higher and lower amounts of yeast extract (Table 3). SVQ582 cultures showed the same $\beta$-galactosidase activity in formulations that differed only in the concentration of mannitol (Table 3, formulations B and C), indicating a lack of correlation between $r k p M$ transcription and mannitol concentration. The presence of 5 or $10 \mathrm{mM} \mathrm{KNO}_{3}$ in YMB formulation containing the lower amount of yeast extract did not alter the LacZ activity of SVQ582 cultures.

Table 3. Effect of the C/N relation in liquid yeast mannitol (YMB) media on the expression of the Sinorhizobium fredii HH103 rkpM gene

\begin{tabular}{|c|c|c|c|}
\hline YMB formulation ${ }^{a}$ & Yeast extract (grams per liter) & Mannitol (grams per liter) & $\beta$-Galactosidase activity \\
\hline A & 1.0 & 1 & $404 \pm 40^{*}$ \\
\hline B & 0.4 & 10 & $303 \pm 10$ \\
\hline $\mathrm{C}$ & 0.4 & 1 & $275 \pm 27$ \\
\hline $\mathrm{D}$ & 0.1 & 10 & $203 \pm 20 *$ \\
\hline $\mathrm{D}+5 \mathrm{mM} \mathrm{KNO}$ & 0.1 & 10 & $219 \pm 23^{*}$ \\
\hline $\mathrm{D}+10 \mathrm{mM} \mathrm{KNO} 3$ & 0.1 & 10 & $215 \pm 39 *$ \\
\hline
\end{tabular}

a Formulation "B" corresponds to the standard YMB composition.

${ }^{\mathrm{b}}$ Shown in Miller units. Data represent averages of three independent experiments, each composed of two replicates. Numbers followed by an asterisk are significantly different $(P<0.01)$ from that of the standard B condition, using the Mann-Whitney nonparametrical test. $\beta$-Galactosidase activity of D cultures with and without $\mathrm{KNO}_{3}$ were not significantly different. 
Symbiotic properties of $S$. fredii $\mathrm{HH103}$ rkpM (SVQ581), rkpP (SVQ667), and $r k p Q$ (SVQ592) mutants with

determinate and indeterminate nodule-forming legumes.

S. fredii HH103 Rif $^{\mathrm{r}}$ nodulates a broad range of legumes, including determinate and indeterminate nodule-forming plants. The symbiotic phenotype of $S$. fredii rkpM, rkpP, and $r k p Q$ mutants was investigated with two determinate nodule-forming legumes (G. max cv. Williams and $V$. unguiculata) and also with $C$. cajan and Glycyrrhiza uralensis, which form indeterminate nodules (Table 4; Fig. 7).

G. $\max \mathrm{cv}$. Williams and V. unguiculata plants inoculated with mutant SVQ581 (rkpM:: $\Omega$ ) showed severe symptoms of nitrogen starvation (Fig. 7B and F). Soybean and cowpea roots inoculated with SVQ581 formed pseudonodules that were devoid of bacteroids (Fig. 7I, L, N, and P) and did not show nitrogenase activity in acetylene reduction assays (data not shown). Inoculation of soybean and cowpea plants with SVQ592 ( $r k p Q:: \Omega)$ and SVQ667 ( $r k p P:: l a c Z)$ also induced the formation of pseudonodules that did not contain bacteroids (Table 4; Fig. 7G). All attempts to isolate bacteria from soybean and cowpea pseudonodules induced by SVQ581, SVQ592, or SVQ667 were unsuccessful.

Mutants SVQ581, SVQ592, and SVQ667 carrying cosmid pMUS664 regained the capacity to induce the formation of nitrogen-fixing nodules in soybean cv. Williams (Table 4; Fig. 7C and J; data not shown).

$S$. fredii $\mathrm{HH} 103$ is fully effective with $C$. cajan (Parada et al. 2006). All the HH103 rkp-3 mutants failed to form nitrogenfixing nodules with $C$. cajan. Most of the pigeon pea roots inoculated with the $S$. fredii $\mathrm{HH} 103$ rkpM, rkpP, or $r k p Q$ mutants developed pseudonodules and macroscopic swellings. $S$. fredii $\mathrm{HH} 103$ rkpM, rkpP, and $r k p Q$ mutants carrying cosmid
pMUS664 formed nodules similar in shape and color to those formed by the wild type with $C$. cajan.

S. fredii HH103 Rif $^{\mathrm{r}}$ effectively nodulates with Glycyrrhiza uralensis, although the number of nodules formed and plant development are highly variable (Table 4; Fig. 7Q and T). Mutants SVQ581 $(r k p M:: \Omega)$ and SVQ592 $(r k p Q:: \Omega)$ were still able to form nitrogen-fixing nodules in about $50 \%$ of the inoculated plants (Table 4; Fig. 7R, S, U, and V). Glycyrrhiza uralensis plants showing better nodulation were also better developed, indicating that, in the experimental conditions used, the development of each particular plant was positively correlated to the number of nitrogen-fixing nodules formed. Acetylene reduction assays confirmed that Glycyrrhiza uralensis nodules induced by mutants SVQ581 and SVQ592 had nitrogenase activity (data not shown). Optical microscopy analyses of Glycyrrhiza uralensis nodules induced by S. fredii $\mathrm{HH} 103$ Rif $^{\mathrm{r}}$ showed plant cells fully invaded by bacteroids (Fig. 7X). Many infected cells had a large vacuole that occupied the center of the cell. In contrast, nodules induced by SVQ581 or SVQ592 showed fewer cells infected (Fig. 7Y and Z). The central vacuole observed in cells of nodules induced by HH103 Rif ${ }^{\mathrm{r}}$ was not so clearly visible in nodules induced by mutants SVQ581 and SVQ592. Similarly, the rkpP mutant (SVQ667) was also able to induce the formation of nitrogenfixing nodules on Glycyrrhiza uralensis roots. Microscopy analyses of nodules induced by SVQ667 were not carried out.

Salicylic acid (SA) production in soybean roots inoculated with $S$. fredii $\mathrm{HH} 103$ Rif $^{\mathrm{r}}$ and its rkpM mutant derivative.

One of the symbiotic functions of rhizobial surface polysaccharides might be the control (suppression) of plant defense responses (Jones et al. 2008; Soto et al. 2009). To test whether

Table 4. Plant responses to inoculation of Glycine max cv. Williams, Vigna unguiculata cv. Bisbee Red, Glycyrrhiza uralensis, and Cajanus cajan with Sinorhizobium fredii HH103 Rif ${ }^{\mathrm{r}}$ and its $r k p M$ (SVQ581 and SVQ582), rkpQ (SVQ592 and SVQ594), and rkpP (SVQ667) mutant derivatives

\begin{tabular}{|c|c|c|c|}
\hline Legume tested & Inoculant $^{\mathrm{a}}$ & Nodulation and nitrogen fixation & Aspect of the plant \\
\hline G. $\max \mathrm{cv}$. Williams ${ }^{\mathrm{b}}$ & $\begin{array}{l}\text { HH103 } \text { Rif }^{\mathrm{r}} \\
\text { SVQ581 } \\
\text { SVQ581 (pMUS664) } \\
\text { SVQ592 } \\
\text { SVQ592 (pMUS664) } \\
\text { SVQ594 } \\
\text { SVQ667 } \\
\text { None }\end{array}$ & $\begin{array}{l}\text { Nitrogen-fixing }\left(\mathrm{Fix}^{+}\right) \text {nodules }(91 \pm 25) \\
\text { Pseudonodules unable to fix nitrogen }\left(\mathrm{Fix}^{-}\right) \\
\text {Fix }^{+} \text {nodules }(91 \pm 18) \\
\text { Pseudonodules, Fix } \\
\text { Fix }{ }^{+} \text {nodules }(64 \pm 30) \\
\text { Pseudonodules, Fix } \\
\text { Pseudonodules Fix } \\
\text { Nod }^{-}\end{array}$ & $\begin{array}{l}\text { Well developed, green leaves } \\
\text { Stunted, yellow leaves } \\
\text { Well developed, green leaves } \\
\text { Stunted, yellow leaves } \\
\text { Well developed, green leaves } \\
\text { Stunted, yellow leaves } \\
\text { Stunted, yellow leaves } \\
\text { Stunted, yellow leaves }\end{array}$ \\
\hline V. unguiculata $^{\mathrm{b}}$ & $\begin{array}{l}\text { HH103 } \text { Rif }^{\mathrm{r}} \\
\text { SVQ581 } \\
\text { SVQ592 } \\
\text { SVQ594 } \\
\text { SVQ667 } \\
\text { None }\end{array}$ & $\begin{array}{l}\text { Fix }{ }^{+} \text {nodules }(60 \pm 15) \\
\text { Pseudonodules, Fix } \\
\text { Pseudonodules, Fix } \\
\text { Pseudonodules, Fix } \\
\text { Pseudonodules, Fix } \\
\text { Nod }^{-}\end{array}$ & $\begin{array}{l}\text { Well developed, green leaves } \\
\text { Stunted, yellow leaves } \\
\text { Stunted, yellow leaves } \\
\text { Stunted, yellow leaves } \\
\text { Stunted, yellow leaves } \\
\text { Stunted, yellow leaves }\end{array}$ \\
\hline Glycyrrhiza uralensis $^{\mathrm{c}}$ & $\begin{array}{l}\text { HH103 Rif } \\
\text { SVQ581 } \\
\text { SVQ592 } \\
\text { SVQ667 } \\
\text { None }\end{array}$ & $\begin{array}{l}\text { Fix }^{+} \text {nodules }(35 / 38) \\
\text { Fix }^{+} \text {nodules }(10 / 17) \\
\text { Fix }^{+} \text {nodules }(9 / 18) \\
\text { Fix }^{+} \text {nodules }(5 / 9) \\
\operatorname{Nod}^{-}(0 / 41)\end{array}$ & $\begin{array}{l}\text { Variable } \\
\text { Variable } \\
\text { Variable } \\
\text { Variable } \\
\text { Stunted, yellow leaves }\end{array}$ \\
\hline C. cajan $^{\mathrm{d}}$ & $\begin{array}{l}\text { HH103 Rif } \\
\text { SVQ582 } \\
\text { SVQ594 } \\
\text { SVQ667 }\end{array}$ & $\begin{array}{l}\text { Fix }{ }^{+} \text {nodules }(87 \pm 30) \\
\text { Pseudonodules, Fix } \\
\text { Pseudonodules, Fix } \\
\text { Pseudonodules, Fix }\end{array}$ & $\begin{array}{l}\text { Well developed, green leaves } \\
\text { Stunted, yellow leaves } \\
\text { Stunted, yellow leaves } \\
\text { Stunted, yellow leaves }\end{array}$ \\
\hline
\end{tabular}

${ }^{a}$ Bacteria were isolated from at least 10 nodules of each inoculant and legume combination that formed Fix ${ }^{+}$nodules. The antibiotic-resistant markers of all nodule isolates were equal to those of their respective strains used as inoculants. All attempts to isolate bacteria from pseudonodules were unsuccessful.

${ }^{\mathrm{b}}$ Two independent plant tests were carried out and numbers in parenthesis are the mean \pm standard deviation of the number of nodules formed. Determinations were made 7 and 5 weeks after inoculation for G. max and V. unguiculata, respectively.

${ }^{\mathrm{c}}$ Data presented here correspond to the total number of plants used in three different experiments. Determinations were made 12 to 17 weeks after inoculation. Numbers in parenthesis represent the fractions representing the number of plants nodulated to the number of plants inoculated. Positive relationship between plant development and nodule number was observed in all inoculation treatments.

${ }^{\mathrm{d}}$ Data presented here correspond to one experiment. Eight plants (in four jars) were inoculated with each rhizobial inoculant. Determinations were carried out 40 days after inoculation. Two plants inoculated with SVQ667 formed one or two nodules that were not analyzed. C. cajan roots showing pseudonodules also formed many root swellings. 


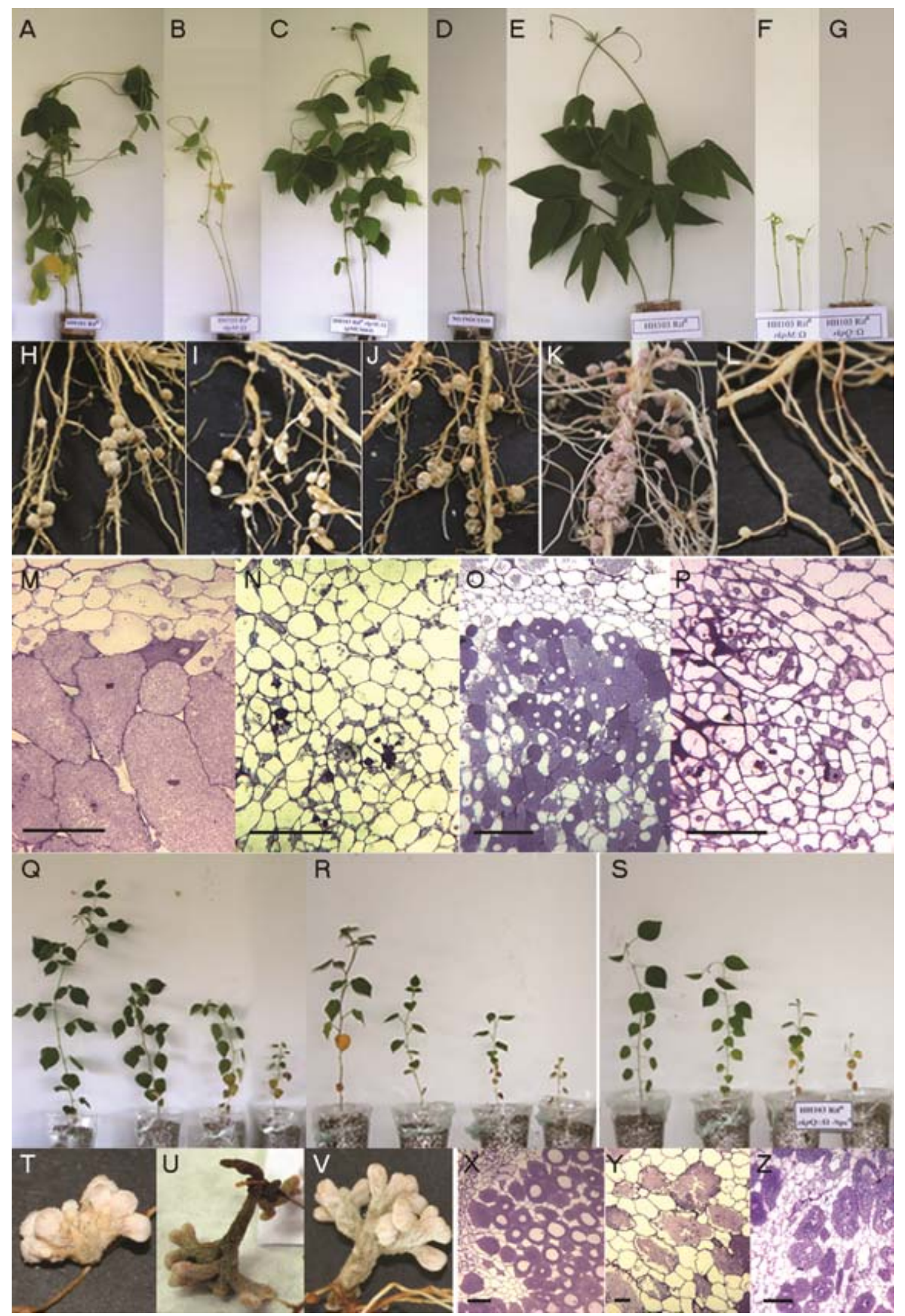

Fig. 7. Plant responses to inoculation of $\mathbf{A}$ to $\mathbf{D}$, and $\mathbf{H}$ to $\mathbf{J}$, Glycine max cv. Williams, $\mathbf{E}$ to $\mathbf{G}$, and $\mathbf{K}$ to $\mathbf{L}$, Vigna unguiculata, and $\mathbf{Q}$ to $\mathbf{Z}$, Glycyrrhiza uralensis with Sinorhizobium fredii HH103 $\mathrm{Rif}^{\mathrm{r}}$ and different $r k p-3$ mutant derivatives. A, Aerial parts of soybean plants inoculated with HH103 Rif ${ }^{\mathrm{r}}$, B, SVQ581 ( $r k p M:: \Omega), \mathbf{C}$, SVQ581 (pMUS664), or D, noninoculated (NI). E, Aerial parts of V. unguiculata plants inoculated with HH103 Rif ${ }^{\mathrm{r}}, \mathbf{F}, \mathrm{SVQ} 581$, or G, SVQ592 $(r k p Q:: \Omega)$. H and M, Macroscopic and microscopic aspect of soybean Williams nodules induced by HH103 Rif ${ }^{\mathrm{r}}$, I and N, SVQ581, and J, SVQ581 (pMUS664). K and O, Macroscopic and microscopic aspect of $V$. unguiculata nodules induced by HH103 Rif ${ }^{\mathrm{r}}$ and $\mathbf{L}$ and $\mathbf{P}, \mathbf{S V Q 5 8 1}$. Q, Aerial parts of Glycyrrhiza uralensis plants inoculated with HH103 Rif ${ }^{\mathrm{r}}$, R, SVQ581, and S, SVQ592. T and X, Macroscopic and microscopic aspect of Glycyrrhiza uralensis nodules induced by HH103 Rif $^{\mathrm{r}}$, U and $\mathbf{Y}$, SVQ581, and V and Z, SVQ592. All uninoculated controls remained nonnodulated. Bar size $=50 \mu \mathrm{m}(\mathrm{M}, \mathrm{N}, \mathrm{P}), 100 \mu \mathrm{m}(\mathrm{X}, \mathrm{Y}, \mathrm{Z})$, or $500 \mu \mathrm{m}(\mathrm{O})$. 
alterations in the $S$. fredii LPS and KPS caused by the loss of function of the rkpM gene could trigger plant defense responses, SA content was determined in soybean roots at different times after inoculation with either the wild type or its SVQ581 $(r k p M:: \Omega)$ mutant derivative. SA measurements were also performed on noninoculated plants to detect any effect in response to rhizobial inoculation. It has been observed that, regardless of the treatment, SA content in soybean roots $12 \mathrm{~h}$ and 1 day after inoculation (dai) is higher compared with the SA content present in older plants, probably reflecting the acclimation of the seedlings to the new growth conditions. Under these experimental conditions, differences in SA levels could be observed only in plants 7 dai (Fig. 8). Whereas soybean roots inoculated with the $\operatorname{rkp} M$ mutant showed similar SA content to that shown by noninoculated plants, plants inoculated with the wild-type strain showed approximately 50\% less SA content. This could indicate that either wild-type LPS or KPS or both produced by $S$. fredii are able to limit the normal synthesis of SA in soybean plants. However, this effect seems to be transient.

\section{DISCUSSION}

In $S$. fredii $\mathrm{HH} 103$ the $r k p-1$ and $r k p-2$ regions are in the chromosome, while the $r k p-3$ region is located in the 2.1-Mbp megaplasmid (Margaret et al. 2011). This megaplasmid also carries genes for the biosynthesis of EPS (exo) and genes involved in LPS production, such as a transporter (homologous to $m b s A$ ) of the LPS lipid A. Thus S. meliloti Rm41, Rhizobium sp. strain NGR234, and $S$. fredii $\mathrm{HH} 103$ show a similar distribution of their three $r k p$ regions. In all cases, only the region ( $r k p-3)$ that contains genes for PseAc biosynthesis ( $r k p L$, $r k p M, r k p N, r k p O, r k p P$, and $r k p Q$ ) is plasmid borne. This situation resembles that described for other bacteria, such as $A$. caviae, in which the genes required for biosynthesis of PseAc are located in a genetic island that might have been laterally acquired.

The $S$. fredii $\mathrm{HH} 103$ rkpL, rkpM, rkpN, rkpO, rkpP, and $r k p Q$ genes are orthologous, respectively, to the pseB, pseC, pseF, pseG, pseH, and pseI genes of Helicobacter pylori, which have been identified as encoding the enzymes of the complete biosynthetic pathway of PseAc from UDP- $N$-acetylglucosamine (Schoenhofen et al. 2006). Although early reports indicated that RkpP might act as an acetyltransferase in $S$. meliloti Rm41 (Kiss et al. 2001), later studies suggest that this enzyme might be involved in the 3-hydroxybutyryl acylation of the Rm41 KPS (Le Quéré et al. 2006). The rkpP gene is present in $S$. meliloti $\mathrm{Rm} 41$ and $S$. fredii $\mathrm{HH} 103$ but absent in Rhizobium sp. strain NGR234. This difference is in agreement with the presence of a 3-hydroxybutyryl residue in the KPS repeating unit of $S$. meliloti Rm41 and S. fredii $\mathrm{HH} 103$ but not in Rhizobium sp. strain NGR234. Taking all these facts together, we propose that the biosynthesis pathway of the $S$. fredii $\mathrm{HH} 103$ KPS repeating units is nearly identical to that described for $H$. pylori (Schoenhofen et al. 2006), but with the difference that the $S$. fredii HH103 RkpP enzyme would add 3-hydroxybutyryl residues instead of the acetyl substituents added by the $H$. pylori PseH enzyme. Figure 9 shows the proposed pathway as well as its putative intermediates, from UDP- $N$-acetylglucosamine to CMP-5-acetamido-3,5,7,9-tetradeoxy-7-(3-hydroxybutyramido)-L-glycero-L-manno-nonulosonic acid, which would correspond to the CMP-activated form of the S. fredii $\mathrm{HH} 103$ KPS repeating unit (Gil-Serrano et al. 1999).

Previous studies performed on S. fredii USDA205 and Rhizobium sp. strain NGR234 have shown that the presence of flavonoids influences KPS production (Reuhs et al. 1994; Simsek et al. 2009). In S. fredii HH103, however, the flavonoid genistein did not significantly alter the transcriptional activity of the rkp-1 genes (Hidalgo et al. 2010; Margaret-Oliver et al. 2012). In this work, we show that genistein does not significantly influence the transcriptional activity of the $r k p M$ gene (in mutant SVQ582), indicating that this flavonoid, which is a major activator of $S$. fredii $\mathrm{HH} 103$ nod genes (Vinardell et al. $2004 \mathrm{a}$ and b), might not have any significant effect on the transcriptional regulation of $\mathrm{HH} 103 r k p-1$ and $r k p-3$ regions. In contrast, this flavonoid represses the mucosity of $S$. fredii HH103 colonies, which indicates an effect over the exopolysaccharide (EPS) produced by this strain (Vinardell et. al. 2004b).

We have also tested whether different formulations of the YMB medium (different amounts of mannitol and yeast extract) affected the expression of the rkpM gene. The higher LacZ activity of SVQ582 cultures correlated with the higher amount of yeast extract present in the medium, which might indicate that an increase of $\mathrm{N}$ availability induces an increase of the rkpM transcription. However, the addition of $\mathrm{KNO}_{3}$ did not increase the LacZ activity of SVQ582, indicating that the yeast extract used might contain a compound that, directly or indirectly, increases the transcription of the $\operatorname{rkp} M:: l a c Z \Delta \mathrm{p}-\mathrm{Gm}^{\mathrm{r}}$ fusion.

The rhizobial KPS expression can also be affected by abiotic factors, such as temperature or $\mathrm{pH}$ (Kanneberg et a. 1998). In $S$. fredii HH103, however, the expression of the rkpM gene was not significantly affected at acidic $(\mathrm{pH} 6.0)$, neutral $(\mathrm{pH}$ 7.0), or alkaline ( $\mathrm{pH} 8.0)$ conditions.

The $S$. fredii $\mathrm{HH} 103$ rkp-1 region appears to be involved in the synthesis of a specific lipid carrier for KPS biosynthesis. All individual mutants affected in each gene of the rkpAGHIJ operon and in the $r k p U$ gene are unable to produce the wild-

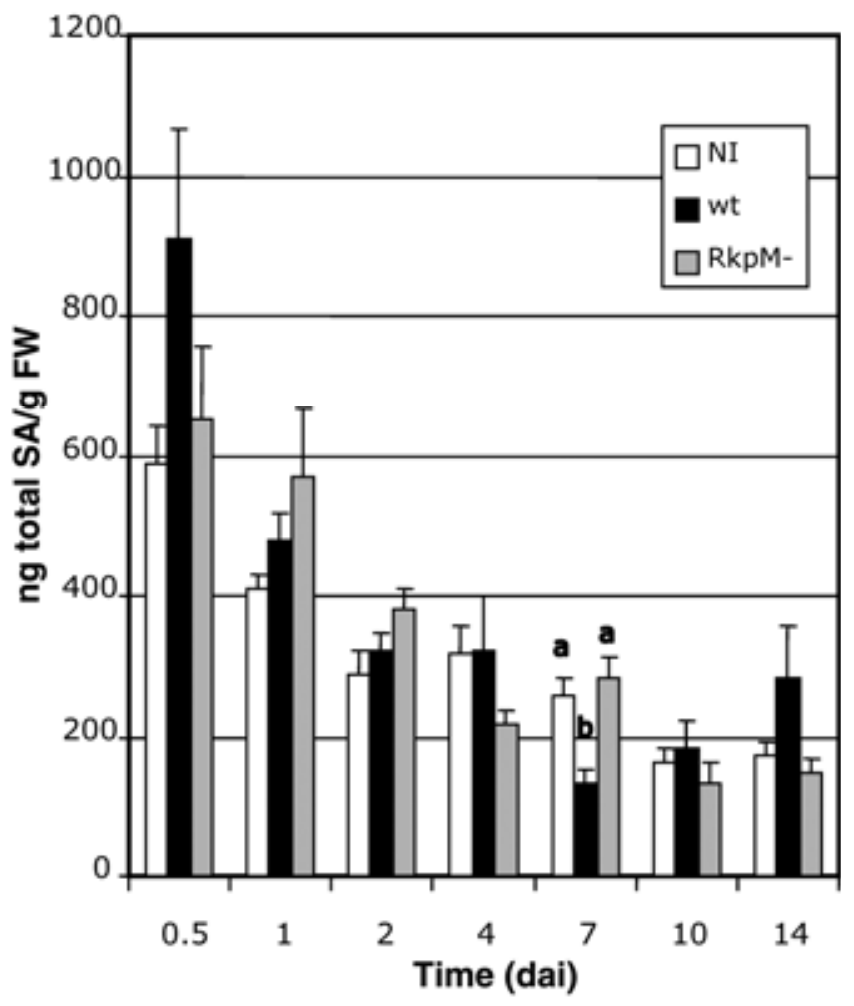

Fig. 8. Total salicylic acid (SA) content in soybean roots. Data represent nonograms of total SA per gram of fresh weight $(\mathrm{FW})$ of soybean roots noninoculated (white bars) and inoculated with the wild-type strain (black bars) or the rkpM mutant strains of Sinorhizobium fredii (gray bars). Results are averages from at least two independent biological experiments with two technical replicates. At least three plants were used for each extraction. Error bars indicate standard error at $95 \%$ confidence, and different letters indicate significant differences according to an analysis of variance test $(P<0.01)$. dai $=$ days after inoculation. 
type KPS (poly-PseAc) and show the same symbiotic phenotype, which varies according to the plant inoculated (Hidalgo et al. 2010; Margaret-Oliver et al. 2012; Parada et al. 2006). All $r k p-1$ mutants showed reduced nodulation and nitrogenfixation capabilities with soybean but not with $V$. unguiculata, which indicates that determinate nodule-forming legumes can show differences in their symbiotic capacity with $S$. fredii HH103 rkp-1 mutants. All these $r k p-1$ mutants were also able to fix nitrogen with indeterminate nodule-forming legumes such as C. cajan or Glycyrrhiza uralensis, although the bacterial symbiotic capacity was reduced in comparison with that of the wild-type $S$. fredii HH103 Rif $^{\mathrm{r}}$ (Margaret-Oliver et al. 2012; Parada et al. 2006).

Although $S$. fredii $\mathrm{HH} 103$ rkp-1 or $r k p-3$ mutants share the characteristic of being unable to produce KPS, they differed in other traits. Mutants in the $r k p-1$ region showed LPS profiles that apparently were indistinguishable from that of the wild-type HH103 Rif ${ }^{\mathrm{r}}$. The only exception was found in mutants of the $r k p U$ gene (which composes a transcriptional unit separated from the rkpAGHIJ operon), which produce altered forms of LPS (Hidalgo et al. 2010). In contrast to most of the $r k p-1$ mutants, all mutants of the $r k p-3$ region (in the $r k p M, r k p P$, or $r k p Q$ genes) showed clear alterations of their LPS profiles in PAGE experiments (Fig. 4) and only formed ineffective, noninfected pseudonodules in soybean, $V$. unguiculata, and C. cajan (Table 4; Figure 7). Thus, S. fredii HH103 mutants in the $r k p-1$ region are still able to form some nitrogen-fixing nodules on soybean and $C$. cajan, while $r k p-3$ mutants only induce the formation of noninfected, ineffective pseudonodules. This difference between the symbiotic capacity of $r k p-1$ and $r k p-3$ mutants is even clearer in $V$. unguiculata; $r k p-1$ mutants appear to be fully effective, while $r k p-3$ mutants only form pseudonodules. Since neither $r k p-1$ nor $r k p-3$ mutants produce the poly-PseAc KPS, the sym- biotic differences found might be due to the LPS alterations detected in the rkp-3 mutants. The fact that the SVQ575 mutant (mutated in $r k p U, \mathrm{KPS}^{-}$, LPS altered) still forms some $\mathrm{Fix}^{+}$nodules on soybean roots could be justified by the following observations. The SVQ575 LPS profile is more similar to that of HH103 Rif $^{\mathrm{r}}$ than to that of $r k p-3$ mutants, and it is still recognized by the monoclonal antibody NB6-228.22 (Hidalgo et al. 2010), which recognizes the $S$. fredii $\mathrm{HH} 103$ wild-type LPS but fails to recognize the altered LPS produced by the $r k p-3$ mutants.

We have not detected differences between Glycyrrhiza uralensis responses to inoculation with $r k p-3$ mutants and those previously described with $r k p-1$ mutants (MargaretOliver et al. 2012). In C. cajan, however, S. fredii HH103 $r k p-1$ mutants are still able to form a few nitrogen-fixing nodules (Parada et al. 2006), while the $r k p-3$ mutants only induce the formation of pseudonodules and root swellings. Thus, indeterminate nodule-forming legumes (such as Glycyrrhiza uralensis and $C$. cajan) also can show different symbiotic responses to the inoculation with $S$. fredii $\mathrm{HH} 103$ $r k p-1$ and $r k p-3$ mutants. In conclusion, S. fredii HH103 LPS not only appear to be more relevant than KPS for the bacterial symbiotic capacity with determinate nodule-forming legumes (soybean or cowpea) but also with $C$. cajan (indeterminate nodules).

Although S. fredii HH103 appears closely related to Rhizobium sp. strain NGR234 (Margaret et al. 2011), their respective $r k p-3$ mutants unable to produce PseAc-containing KPS show clear phenotypic differences. An NGR234 mutant carrying a deletion of $r k p M, r k p N$, and $r k p O$ was still able to form nitrogen-fixing nodules with $V$. unguiculata and its LPS was apparently unaffected (Le Quéré et al. 2006).

A. caviae $\mathrm{Sch} 3 \mathrm{~N}$ has a small genomic island that is involved in flagellin glycosylation and in the biosynthesis of PseAc and

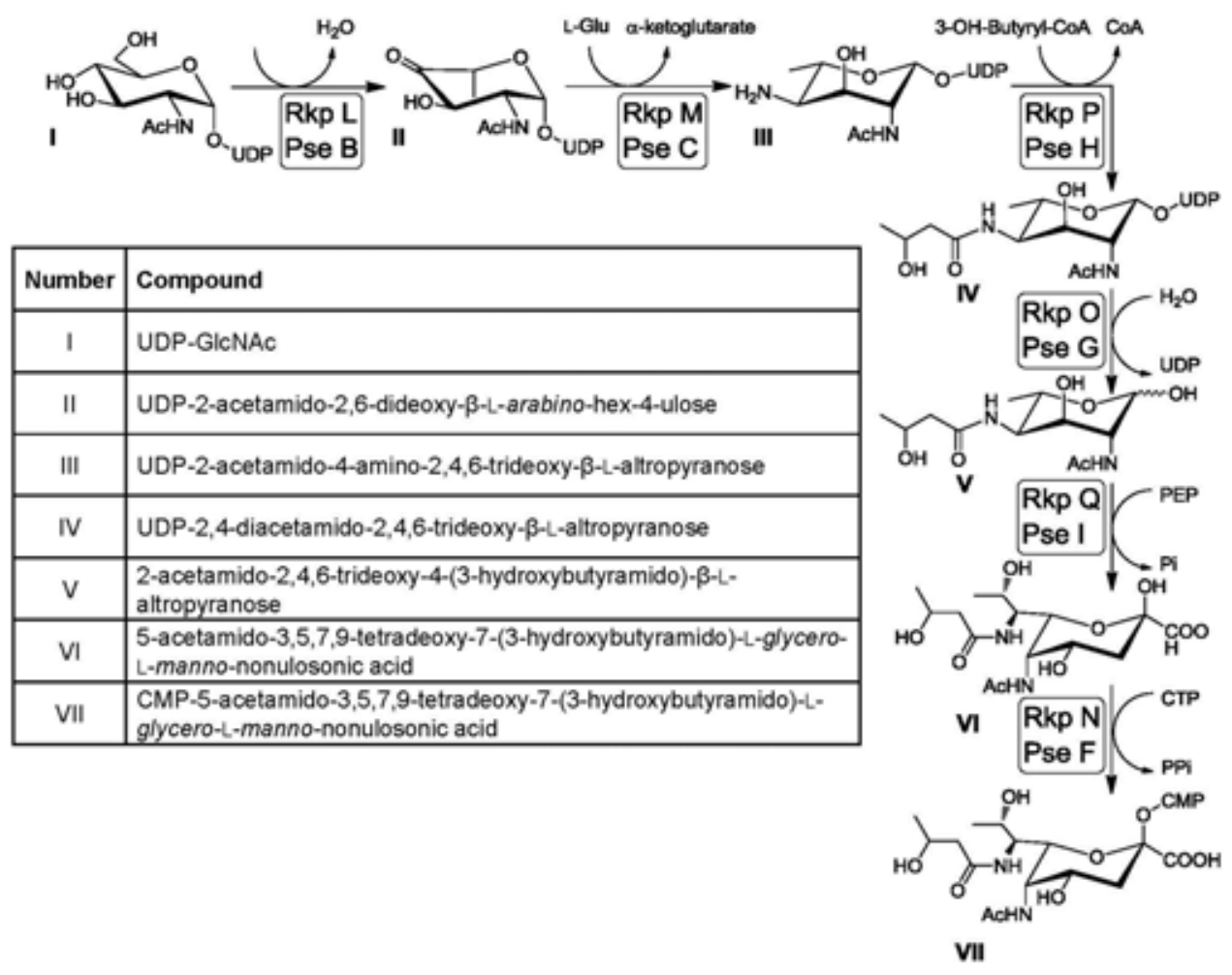

Fig. 9. A proposal for the pseudaminic acid pathway in Sinorhizobium fredii HH103. This proposal is based on the CMP-pseudaminic acid biosynthetic pathway proposed in Helicobacter pylori and Campylobacter jejuni (Schoenhofen et al. 2006). Pseudaminic enzymes are included to indicate putative functional similitude with Rkp enzymes, although the reaction products vary from compound IV, which is acetylated in $H$. pylori but would be butyrylated in $S$. fredii HH103. 
the LPS O-antigen (Tabei et al. 2009). Five genes of the $A$. caviae island $(f \operatorname{lm} A, f \operatorname{lm} B, n e u A, f l m D$, and $n e u B)$ are orthologous, respectively, to the $S$. fredii $\mathrm{HH} 103 \operatorname{rkpL}, \operatorname{rkpM}, \operatorname{rkpN}, \operatorname{rkpO}$, and $r k p Q$ genes. This island appears to have been laterally acquired as it is flanked by insertion element-like sequences and has a much lower $\mathrm{G}+\mathrm{C}$ content $(42 \%)$ than the average A. caviae $\mathrm{C}+\mathrm{G}$ content (60\%). Similarly, transposon sequences (b1962 and b1963) appear in the vicinity of the $S$. fredii HH103 rkpQ gene and the $\mathrm{G}+\mathrm{C}$ content $(54.4 \%)$ of the sequenced fragment containing the $r k p L, r k p M, r k p N, r k p O, r k p P$, and $r k p Q$ genes (JN642175) was lower than that calculated for the entire 2.1Mbp plasmid $(62.3 \%)$ or the chromosome $(62.6 \%)$. Thus, $S$. fredii $\mathrm{HH} 103$ could also have acquired the $r k p-3$ genes involved in PseAc biosynthesis by lateral transfer.

A. caviae mutants affected in any of these five genes have lost bacterial motility and flagellar expression and their LPS profile is altered. In $A$. hydrophila, however, mutations in the $f \operatorname{lm} A, f \operatorname{lm} B, n e u A, f \operatorname{lm} D$, and neuB genes affect only motility and flagellar expression but do not cause any alteration in the LPS (Canals et al. 2007; Gryllos et al. 2001). The major modification identified on flagellin from Campylobacter jejuni 81176 and A. caviae is the presence of PseAc (Guerry et al. 2006; Tabei et al. 2009). Mutants that produce flagella lacking PseAc failed to autoagglutinate and showed reduced pathogenicity (Guerry et al. 2006; Power and Jennings 2003; Tabei et al. 2009). Thus, PseAc appears to be involved in LPS biosynthesis and flagellar assembly of $A$. caviae. Similarly to the A. caviae flmB and neuB mutants, $S$. fredii $\mathrm{HH} 103$ rkpM, rkpP, and $r k p Q$ mutants also show alteration in their LPS profiles, which might indicate that PseAc or a derivative might be involved in $S$. fredii HH103 LPS biosynthesis. In contrast, $S$. fredii rkpM and $\operatorname{rkp} Q$ mutants differ from $A$. caviae flmB and $n e u B$ mutants in those characteristics that could be attributed to changes in flagella, i.e., they are still able to swim (although their motility is reduced) and show enhanced auto-agglutination. Most probably, the reduced motility exhibited by HH103 rkp3 mutants is not due to a lower growth capacity, since strains SVQ581, SVQ592, and HH103 Rif ${ }^{\mathrm{r}}$ grew equally well in YMB medium (data not shown). Whether $S$. fredii $\mathrm{HH} 103$ flagellin carries PseAc substitutions is an interesting question to further investigate the parallelisms between KPS functions in symbiotic and pathogenic bacteria.

\section{MATERIALS AND METHODS}

Molecular and microbiological techniques.

The bacterial strains and plasmids used in this work are listed in Table 5. S. fredii strains were grown at $28^{\circ} \mathrm{C}$ on TY medium (Beringer 1974) or YM medium (Vincent 1970). Escherichia coli was cultured on Luria-Bertani medium (Sambrook et al. 1989) at $37^{\circ} \mathrm{C}$. When required, the media were supplemented with the appropriate antibiotics as described by Vinardell and associates (2004a). Flavonoids were dissolved in ethanol at a concentration of $1 \mathrm{mg} \mathrm{ml}^{-1}$ and used at $1 \mu \mathrm{g} \mathrm{ml}^{-1}$. Plasmids were transferred from $E$. coli to rhizobia by conjugation as described by Simon (1984).

Motility assays were performed as previously described (Crespo-Rivas et al. 2009). For bacterial auto-agglutination assays, liquid cultures of $S$. fredii strains were incubated at $28^{\circ} \mathrm{C}$ on an orbital shaker at $180 \mathrm{rpm}$ until they reached the earlystationary phase (about $\mathrm{OD}_{660}=1.0$ ). Then, $4.5-\mathrm{ml}$ aliquots of bacterial cultures were transferred to tubes and were incubated at $28^{\circ} \mathrm{C}$ under static conditions. Bacterial auto-agglutination was estimated by measuring the $\mathrm{OD}_{660}$ of the cultures after 1 , 4 , and $24 \mathrm{~h}$ of incubation.

Assays for $\beta$-galactosidase activity in liquid bacterial cultures on YMB were carried out $16 \mathrm{~h}$ after induction, as previously described (Vinardell et al. 2004a). At least three independent experiments performed in duplicate were carried out.

Recombinant DNA techniques were performed according to the general protocols of Sambrook and associates (1989). For hybridization, DNA was blotted to Amersham HybondTM-N nylon membranes (GE Healthcare, Piscataway, NJ. U.S.A.), and the DigDNA method of Roche (Mannheim, Germany) was employed according to manufacturer's instructions. PCR amplifications were performed as previously described (Vinardell et al. 2004b). All primers pairs used in this work are listed in Table 1.

Table 5. Bacterial strains and plasmids

\begin{tabular}{|c|c|c|}
\hline Strain or plasmid & Derivation and relevant properties $^{a}$ & Source or reference \\
\hline \multicolumn{3}{|l|}{ Sinorhizobium fredii } \\
\hline HH103 Rif ${ }^{\mathrm{r}}(=\mathrm{SVQ} 269)$ & Spontaneous Rif ${ }^{\mathrm{r}}$ derivative of $\mathrm{HH} 103$ & Madinabeitia et al. 2002 \\
\hline SVQ581 & HH103 Rif ${ }^{\mathrm{r}} r k p M:: \Omega$ & This work \\
\hline SVQ582 & HH103 Rif ${ }^{\mathrm{r}} r k p M:: l a c Z \Delta \mathrm{p}-\mathrm{Gm}^{\mathrm{r}}$ & This work \\
\hline SVQ592 & HH103 Rif ${ }^{\mathrm{r}} r p Q:: \Omega$ & This work \\
\hline SVQ594 & 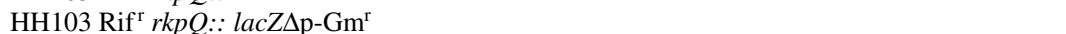 & This work \\
\hline SVQ667 & HH103 $\operatorname{Rif}^{\mathrm{r}} r k p P:: \Omega$ & This work \\
\hline \multicolumn{3}{|l|}{ Escherichia coli } \\
\hline $\mathrm{DH} 5 \alpha$ & supE44 $\Delta$ lacU169 hsdR17 racAl endA1 gyr96 thi-1 relA1, $\mathrm{Nx}^{\mathrm{r}}$ & Stratagene \\
\hline \multicolumn{3}{|l|}{ Plasmids } \\
\hline pAB2001 & $A p^{r}$ vector containing the $l a c Z \Delta p-G^{r}$ cassette & Becker et al. 1995 \\
\hline pBluescript II SK+ & Cloning and sequencing vector, $\mathrm{Ap}^{\mathrm{r}}$ & Stratagene \\
\hline $\mathrm{pHP} 45 \Omega$ & $\mathrm{Ap}^{\mathrm{r}}$ vector containing the $\Omega$ interposon $\left(\mathrm{Spc}^{\mathrm{r}} \mathrm{Str}^{\mathrm{r}}\right)$ & Prentki and Krisch 1984 \\
\hline pK18mob & Cloning vector, $\mathrm{Km}^{\mathrm{r}}$ & Schäfer et al. 1994 \\
\hline pMUS664 & Cosmid pLAFR 1 carrying the $r k p L M N O P Q$ genes of the $r k p-3$ region of $S$. fredii $\mathrm{HH} 103$ & This work \\
\hline pMUS955 & pK18mob derivative containing the $r k p M N$ genes of $S$. fredii $\mathrm{HH} 103$ & This work \\
\hline pMUS960 & pMUS955 derivative containing $\mathrm{HH} 103$ rkpM:: & This work \\
\hline pMUS964 & pMUS955 derivative containing HH103 rkpM::lacZ $\Delta$ p-Gm ${ }^{\mathrm{r}}$ & This work \\
\hline pMUS893 & pBluescript II SK+ containing HH103 rkpQ & This work \\
\hline pMUS953 & pMUS893 derivative containing HH103 $r k p Q:: \Omega$ & This work \\
\hline pMUS951 & pMUS893 derivative in which two 30 and 600-bp EcoRI-SalI fragments have been eliminated & This work \\
\hline pMUS966 & 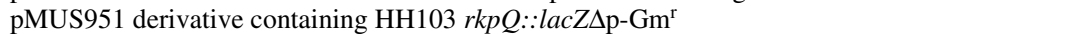 & This work \\
\hline pMUS972 & 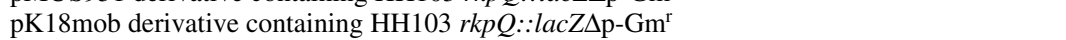 & This work \\
\hline pMUS1032 & pBluescript II SK+ containing HH103 rkpP & This work \\
\hline pMUS1039 & 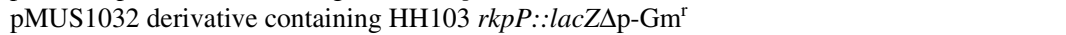 & This work \\
\hline pMUS1040 & 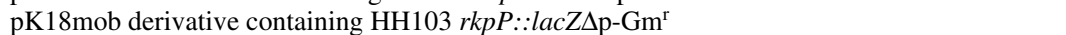 & This work \\
\hline
\end{tabular}

${ }^{\mathrm{a}} \mathrm{Rif}^{\mathrm{r}}, \mathrm{Nx}^{\mathrm{r}}, \mathrm{Ap}^{\mathrm{r}}, \mathrm{Gm}^{\mathrm{r}}, \mathrm{Spc}^{\mathrm{r}}, \mathrm{Str}^{\mathrm{r}}$, and $\mathrm{Km}^{\mathrm{r}}$ = resistant to rifampicin, nalidixic acid, ampicillin, gentamycin, spectinomycin, streptomycin, and kanamycin. 


\section{Construction of mutants.}

In order to generate $r k p$ mutants of $S$. fredii $\mathrm{HH} 103 \mathrm{Rif}^{\mathrm{r}}$, we constructed derivatives of pK18mob (a kanamycin-resistant $\left[\mathrm{Km}^{\mathrm{r}}\right]$ suicide vector in rhizobia), carrying the $S$. fredii rkpM, rkpP, or rkpQ coding sequences interrupted by the $\Omega$ (spectinomycin resistant $\left.\left[\mathrm{Spc}^{\mathrm{r}}\right]\right)$ interposon or the lacZ $\Delta \mathrm{p}-\mathrm{Gm}^{\mathrm{r}}$ cassette.

To isolate $S$. fredii HH103 Rif $^{\mathrm{r}}$ rkpM mutants, a 2.4-kb BglII fragment of cosmid pMUS664 that contains the $3^{\prime}$ end of $r k p L$, the complete $r k p M$ and $r k p N$ genes and the $5^{\prime}$ end of $r k p O$ was subcloned into pK18mob, thus generating plasmid pMUS955. Plasmids pMUS960 and pMUS964 were constructed, respectively, by subcloning the $\Omega\left(\mathrm{Spc}^{\mathrm{r}}\right.$ ) interposon (as a 2-kb Bam HI fragment from $\mathrm{pMP} 45 \Omega$ ) or the $l a c Z \Delta \mathrm{p}-\mathrm{Gm}^{\mathrm{r}}$ cassette (as a 4.5 $\mathrm{kb}$ BamHI fragment from pAB2001) into the unique BamHI site of $r k p M$ cloned in pMUS955.

To isolate $S$. fredii $\mathrm{HH} 103 \mathrm{Rif}^{\mathrm{r}} \operatorname{rkp} Q$ mutants, a $2.5-\mathrm{kb}$ EcoRI fragment of cosmid pMUS664 containing the complete $r k p Q$ gene was subcloned into pBluescript $\mathrm{KS}$, generating plasmid pMUS893. Plasmid pMUS953 was constructed by subcloning the $\Omega\left(\mathrm{Spc}^{\mathrm{r}}\right)$ interposon (as a 2-kb BamHI fragment) into the unique $B a m \mathrm{HI}$ site of $r k p Q$ cloned in pMUS893. To insert the $l a c Z \Delta \mathrm{p}-\mathrm{Gm}^{\mathrm{r}}$ cassette into the $r k p Q$ coding region, plasmid pMUS893 was digested with EcoRI and SalI (to remove the SphI site of the cloning vector pBluescriptKS) generating a new plasmid (pMUS951) whose unique $S p h \mathrm{I}$ site is situated in the $\operatorname{rkp} Q$ coding region. Then, the $l a c Z \Delta \mathrm{p}-\mathrm{Gm}^{\mathrm{r}}$ cassette (as a 4.3-kb SphI fragment from pAB2001) was subcloned into the unique $S p h$ I site of $r k p Q$ cloned in pMUS951, generating plasmid pMUS966. The $r k p Q:: l a c Z \Delta \mathrm{p}-\mathrm{Gm}^{\mathrm{r}}$ fusion was subcloned (as a 3.8-kb EcoRISalI fragment from pMUS966) into pK18mob, generating plasmid pMUS972.

To isolate a $S$. fredii $\mathrm{HH} 103 \mathrm{Rif}^{\mathrm{r}}$ rkpP mutant, primers designed from the $r k p O$ and $r k p Q$ coding sequences ( $\mathrm{HH} r k p$ Pext-F and HHrkpPext-R) were used to amplify the complete $r k p P$ gene. The nucleotide sequence of primers HHrkpPext-F and $\mathrm{HH} r k p P$ ext-R was appropriately modified to generate new BamHI restriction sites (Table 1). Using cosmid pMUS664 as template, primers HHrkpPext-F and HHrkpPext-R led to the PCR amplification of a 1,180-bp BamHI fragment that was subcloned into pBluescriptKS, generating plasmid pMUS1032. Plasmid pMUS1039 was constructed by subcloning the lacZ $\Delta \mathrm{p}-\mathrm{Gm}^{\mathrm{r}}$ cassette (as a 4.3-kb $S p h \mathrm{I}$ fragment) into the unique $S p h \mathrm{I}$ site of $r k p P$ cloned in pMUS1032. Then, plasmid pMUS1040 was constructed by subcloning a 5.5-kb BamHI fragment from pMUS1032 (containing the $r k p P:: l a c Z \Delta \mathrm{p}-\mathrm{Gm}^{\mathrm{r}}$ fusion) into plasmid $\mathrm{pK} 18 \mathrm{mob}$.

The different pK18mob derivatives carrying the $r k p M$, $r k p O$, or $r k p P$ genes interrupted by the $\Omega\left(\mathrm{Spc}^{\mathrm{r}}\right)$ interposon or the $l a c Z \Delta \mathrm{p}-\mathrm{Gm}^{\mathrm{r}}$ cassette were individually transferred to HH103 Rif ${ }^{\mathrm{r}}$ in triparental conjugations, using plasmid pRK2013 as the helper plasmid. Rif ${ }^{\mathrm{r}} \mathrm{Spc}^{\mathrm{r}} \mathrm{Km}^{\mathrm{s}}$ (for constructions containing the $\Omega$ interposon) or $\mathrm{Rif}^{\mathrm{r}} \mathrm{Gm}^{\mathrm{r}} \mathrm{Km}^{\mathrm{s}}$ (for the lac $\mathrm{Z} \Delta \mathrm{p}-\mathrm{Gm}^{\mathrm{r}}$ cassette) transconjugants were identified in order to obtain putative double recombinants in which the wild-type $r k p$ gene has been substituted by the mutated copy

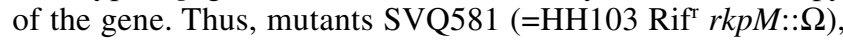
SVQ582 (=HH103 Rif $^{\mathrm{r}}$ rkpM::lacZ $\left.\Delta \mathrm{p}-\mathrm{Gm}^{\mathrm{r}}\right), \quad$ SVQ592

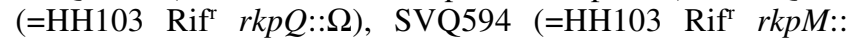

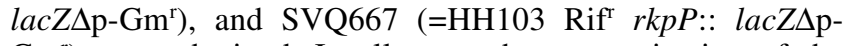
$\mathrm{Gm}^{\mathrm{r}}$ ) were obtained. In all cases, homogenetization of the mutated version of the $r k p$ gene was confirmed by PCR and DNA-DNA hybridization. Primers used for the amplification of $r k p M, r k p P$, or $r k p Q$ coding sequences as well as for mutant derivatives carrying the $\Omega$ interposon or the $\operatorname{lac} Z \Delta \mathrm{p}-\mathrm{Gm}^{\mathrm{r}}$ cassette are listed in Table 1.
PAGE analysis of LPS and KPS.

LPS extraction from bacterial cultures grown on solid TY medium, separation on SDS-PAGE gels, and silver staining were performed as described previously (Buendía-Clavería et al. 2003). Immuno-staining procedures and the monoclonal antibody NB6-228.22 were as described by Buendía-Clavería and associates (2003). KPS were extracted from bacterial cultures grown on solid TY medium, as described by Hidalgo and associates (2010). Samples were analyzed by PAGE as described by Parada and associates (2006), but absolute ethanol was added to the running buffer as well as to the running and stacking gels at a final concentration of $10 \%(\mathrm{vol} / \mathrm{vol})$ in all cases. The acrylamide concentration of the running gel was $18 \%\left(\mathrm{wt} / \mathrm{vol}\right.$ ), and the acrylamide/, $\mathrm{N}^{\prime}$-methylenebisacrylamide ratio was 29:1. Gels were fixed using Alcian Blue $(0.5 \%$ in $2 \%$ acetic acid) and silver staining.

\section{NMR analysis of KPS.}

For the detection of KPS by NMR, S. fredii SVQ581 and SVQ592 were cultured as follows. TY liquid medium (3 liters) was inoculated with $100 \mathrm{ml}$ of early stationary-phase cultures of bacteria and were incubated on an orbital shaker at $180 \mathrm{rpm}$ for 3 days at $28^{\circ} \mathrm{C}$. After incubation, the cells were harvested by slow-speed centrifugation. Bacterial pellets were washed three times with $0.9 \%$ (wt/vol) $\mathrm{NaCl}$, were freeze dried, and were stored in sealed bottles at room temperature. Bacterial polysaccharides were extracted from the freeze-dried bacterial cells $(5 \mathrm{~g})$ with a $1: 1$ hot phenol and water mixture $(100 \mathrm{ml})$, and the two phases were separated (Westphal and Jan 1965). The aqueous phase was dialyzed against water, was treated with an ion-exchange resin IRA400 $\left(\mathrm{AcO}^{-}\right)$, and was freeze dried.

Cell extract samples were deuterium-exchanged several times by freeze drying from ${ }^{2} \mathrm{H}_{2} \mathrm{O}$ and were then examined in solution ( $5 \mathrm{mg}$ of sample in $750 \mu \mathrm{l}$ of $99.98 \%{ }^{2} \mathrm{H}_{2} \mathrm{O}$ ) by ${ }^{1} \mathrm{H}-$ NMR. Spectra were recorded at $303 \mathrm{~K}$ on a Bruker AV500 spectrometer operating at $500.20 \mathrm{MHz}$. Chemical shifts are given in parts per million (ppm), using the $\mathrm{H}^{2} \mathrm{HO}$ signal (4.71 ppm) as reference.

\section{Plant assays.}

Nodulation assays on Glycine max (L.) Merr. cv. Williams, Vigna unguiculata cv. Bisbee Red (L.) Walp, Glycyrrhiza uralensis Fisch, and Cajanus cajan (L.) Millsp. were carried out as previously described (Buendía-Clavería et al. 1989; CrespoRivas et al. 2007). Germinated seeds were transferred to Leonard jars containing sterilized vermiculite supplemented with Fåhraeus nutrient solution (Vincent 1970). Each plant was inoculated with approximately $10^{8}$ bacteria and were then grown for at least 6 weeks with a 16-h photoperiod at $25^{\circ} \mathrm{C}$ in the light and $18^{\circ} \mathrm{C}$ in the dark. Plant tops were dried at $70^{\circ} \mathrm{C}$ for $48 \mathrm{~h}$ and were weighed. Bacterial isolation from surface-sterilized nodules was carried out as previously described by Buendía-Clavería and associates (2003).

\section{Determination of $\mathrm{SA}$ content in soybean roots.}

Soybean plants were grown as described above and were inoculated with $1 \mathrm{ml}$ of the appropriate $S$. fredii culture grown in TY broth up to an $\mathrm{OD}_{600}$ of 0.6 to 0.8 (approximately $10^{8}$ bacteria). Control plants were inoculated with $1 \mathrm{ml}$ of TY broth. Plant roots were collected at different times after inoculation, were frozen in liquid nitrogen, and were kept at $-80^{\circ} \mathrm{C}$ until their use for SA measurement.

SA measurements were basically performed as previously described (Stacey et al. 2006). For each sample, 0.3 to $0.6 \mathrm{~g}$ of the frozen tissue was extracted and quantitated for total SA, free and SA $\beta$-glucoside, essentially as described previously 
(Bowling et al. 1994; Enyedi et al. 1992). Root methanolic extracts $(2 \mu \mathrm{l}$ from a total volume of $80 \mu \mathrm{l})$ were injected into a $3-\mu \mathrm{m}$ Waters Spherisorb S3 ODS2 column $(4.6 \times 150 \mathrm{~mm})$. SA was separated isocratically with $30 \%$ (vol/vol) methanol containing $1 \%(\mathrm{vol} / \mathrm{vol})$ acetic acid at a flow rate of $1.1 \mathrm{ml}$ $\min ^{-1}$. The temperature of the oven was $35^{\circ} \mathrm{C}$. SA was detected with a Varian Prostar fluorescence detector using an excitation wavelength of $313 \mathrm{~nm}$ and an emission wavelength of $405 \mathrm{~nm}$.

\section{ACKNOWLEDGMENTS}

This work was supported by grants from the Spanish Ministry of Science and Innovation (BIO2008-05736-C02-02 and BIO2011-30229-C0201) and the Andalusia Government (P07-CVI-02506).

\section{LITERATURE CITED}

Becker, A., Schmidt, M., Jäger, W., and Pühler, A. 1995. New gentamycinresistance and lac Z promote-probe cassettes suitable for insertion mutagenesis and generation of transcriptional fusions. Gene 162:37-39.

Becker, A., Fraysse, N., and Sharypova, L. 2005. Recent advances in studies on structure and symbiosis-related function of rhizobial K-antigens and lipopolysaccharides. Mol. Plant-Microbe Interact. 18:899-905.

Beringer, J. E. 1974. R factor transfer in Rhizobium leguminosarum. J. Gen. Microbiol. 84:188-198.

Bowling, S. A., Guo, A., Cao, H., Gordon, A. S., Klessig, D. F., and Dong, X. 1994. A mutation in Arabidopsis that leads to constitutive expression of systemic acquired resistance. Plant Cell 6:1845-1857.

Breedveld, M. W., and Miller, K. J. 1998. Cell-surface $\beta$-glucans. Pages 81-96 in: The Rhizobiaceae. Molecular Biology of Model Plant-Associated Bacteria. H. P. Spaink, A. Kondorosi, and P. J. J. Hooykaas. eds. Kluwer Academic Publishers. Dordrecht, The Netherlands.

Buendía-Clavería, A. M., Chamber, M., and Ruiz-Sainz, J. E. 1989. A comparative study of the physiological characteristics, plasmid content and symbiotic properties of different Rhizobium fredii strains. Syst. Appl. Microbiol. 12:203-209.

Buendía-Clavería, A. M., Moussaid, A., Ollero, F. J., Vinardell, J. M., Torres, A., Moreno, J., Gil-Serrano, A. M., Rodríguez-Carvajal, M. A., Tejero-Mateo, P., Peart, J. L., Brewin, N. J., and Ruiz Sainz, J. E. 2003. A purL mutant of Sinorhizobium fredii $\mathrm{HH} 103$ is symbiotically defective and altered in its lipopolysaccharide. Microbiology 149:1807-1818.

Canals, R., Vilches, S., Wilhelms, M., Shaw, J. G., Merino, S., and Tomás J. M. 2007. Non-structural flagella genes affecting both polar and lateral flagella mediated motility in Aeromonas hydrophila. Microbiology 153:1165-1175.

Chataigné, G., Couderc, F., and Poinsot, V. 2008. Polysaccharides analysis of sinorhizobial capside by on-line anion exchange chromatography with pulse amperiometric detection and mass spectrometry coupling. J. Chromatogr. A 1185:241-250.

Crespo-Rivas, J. C, Margaret, I., Pérez-Montaño, F., López-Baena, F. J., Vinardell, J. M., Ollero, F. J., Moreno, J., Ruiz-Sainz, J. E., and Buendía-Clavería, A. M. 2007. A pyrF auxotrophic mutant of Sinorhizobium fredii $\mathrm{HH} 103$ is impaired in its symbiotic interactions with soybean and other legumes. Int. Microbiol. 10:169-176.

Crespo-Rivas, J. C., Margaret, I., Hidalgo, A., Buendía-Clavería, A. M., Ollero, F. J., López-Baena, F. J., del Socorro Murdoch, P., RodríguezCarvajal, M. A., Soria-Díaz, M. E., Reguera, M., Lloret, J., Sumpton, D. P., Mosely, J. A., Thomas-Oates, J. E., van Brussel, A. A. N., GilSerrano, A., Vinardell, J. M., and Ruiz-Sainz, J. E. 2009. Sinorhizobium fredii $\mathrm{HH} 103$ cgs mutants are unable to nodulate determinate- and indeterminate-nodule forming legumes and overproduce an altered EPS. Mol. Plant-Microbe Interact. 22:575-588.

Enyedi, A. J., Yalpani, N., Silverman P., and Raskin, I. 1992. Localization, conjugation, and function of salicylic acid in tobacco during the hypersensitive reaction to tobacco mosaic virus. Proc. Natl. Acad. Sci. U.S.A. 89:2480-2484.

Fraysse, N., Couderc, F., and Poinsot, V. 2003. Surface polysaccharide involvement in establishing the Rhizobium-legume symbiosis. Eur. J. Biochem. 270:1365-1380.

Fraysse, N., Lindner, B., Kaczynski, Z., Sharypova, L., Holst, O., Niehaus, K., and Poinsot, V. 2005. Sinorhizobium meliloti strain 1021 produces a low-molecular-mass capsular polysaccharide that is a homopolymer of 3-deoxy-D-manno-oct-2-ulosonic acid harboring a phospholipid anchor. Glycobiology 15:101-108.

Gage, D. J. 2004. Infection and invasion of roots by symbiotic, nitrogenfixing rhizobia during nodulation of temperate legumes. Mol. Biol. Rev. $68: 280-300$
Geiger, O., and López-Lara, I. M. 2002. Rhizobial acyl carrier proteins and their roles in the formation of bacterial cell-surface components that are required for the development of nitrogen-fixing root nodules on legume hosts. FEMS (Fed. Eur. Microbiol. Soc.) Microbiol. Lett. 208:153-162.

Gil-Serrano, A. M, Rodríguez-Carvajal, M. A., Tejero-Mateo, P., Espartero, J. L., Menendez, M., Corzo, J., Ruiz-Sainz, J. E., and Buendía-Clavería, A. M. 1999. Structural determination of a 5-acetamido-3,5,7,9-tetradeoxy-7-(3-hydroxybutyramido)-L-glycero-L-manno-nonusolonic acidcontaining homopolysaccharide isolated from Sinorhizobium fredii HH103. Biochem. J. 342:527-535.

Gryllos, I., Shaw, J. G., Gavín, R., Merino, S., and Tomás, J. M. 2001. Role of flm locus in mesophilic Aeromonas adherente. Infect. Immun. 69:6574.

Guerry, P., Ewing, C. P., Schirm, M., Lorenzo, M., Kelly, J., Pattarini, D., Majan, G., Thibault, P., and Logan, S. 2006. Changes in flagellin glycosylation affect Campylobacter autoagglutination and virulence. Mol. Microbiol. 60:299-311.

Hidalgo, A., Margaret, I., Crespo-Rivas, J. M., Parada, M., Murdoch, P. S., López, A., Buendía-Clavería, A. M., Moreno, J., Albareda, M., GilSerrano, A. M., Rodríguez-Carvajal, M. A., Palacios, J. M., Ruiz-Sainz, J. E., and Vinardell, J. M. 2010. The rkpU gene of Sinorhizobium fredii $\mathrm{HH} 103$ is required for bacterial $\mathrm{K}$-antigen polysaccharide production and for efficient nodulation with soybean but not with cowpea. Microbiology 156:3398-3411.

Jones, K. M., Kobayashi, H., Davies, B. W., Taga, M. E., and Walker, G. C. 2007. How rhizobial symbionts invade plants: The SinorhizobiumMedicago model. Nature Rev. Microbiol. 5:619-633.

Jones, K. M., Sharopova, N., Lohar, D. P., Zhang, J.Q., VandenBosch, K. A., and Walker, G. C. 2008. Differential response of the plant Medicago truncatula to its symbiont Sinorhizobium meliloti or an exopolysaccharide-deficient mutant. Proc. Natl. Acad. Sci. U.S.A. 105:704-709.

Kannenberg, E. L., Reuhs, B. L., Fosberg, L. S., and Carlson, R. W. 1998. Lipopolysaccharides and K-antigens: Their structures, biosynthesis Pages 119-154 in: The Rhizobiaceae. Molecular Biology of Model Plant-Associated Bacteria. H. P. Spaink, A. Kondorosi, and P. J. J. Hooykaas, eds. Kluwer Academic Publishers, Dordrecht, The Netherlands.

Kereszt, A., Kiss, E., Rehus, B. L., Carlson, R. W., Kondorosi, A,. and Putnoky, P. 1998. Novel rkp gene clusters of Sinorhizobium meliloti involved in capsular polysaccharide production and invasion of the symbiotic nodule: The $r k p K$ gene codes a UDP-glucose dehydrogenase. J. Bacteriol. 180:5426-5431.

Kiss, E., Kereszt, A., Barta, F., Stephens, S., Reuhs, B. L., Kondorosi, A., and Putnoky, P. 2001. The rkp-3 gene region of Sinorhizobium meliloti Rm41 contains strain-specific genes that determinate $\mathrm{K}$ antigen structure. Mol. Plant-Microbe Interact. 14:1395-1403.

Kosslak, R. M., Bookland, R., Barkei, J., Paaren, H. E., and Appelbaum E. R. 1987. Induction of Bradyrhizobium japonicum common nod genes by isoflavones isolated from Glycine max. Proc. Natl. Acad. Sci. U. S. A. 84:7428-7432.

Krishnan, H. B., and Pueppke, S. G. 1993. Characterization of RFRS9, a second member of the Rhizobium fredii repetitive sequence family from the nitrogen-fixing symbiont $R$. fredii USDA257. Appl. Environ. Microbiol. 59:150-155

Krol, E., and Becker, A. 2009. Surface polysaccharides as fitness factors of rhizospheric nitrogen-fixing bacteria. Pages 187-211 in: Bacterial Polysaccharides: Current Innovations and Future Trends. M. Ullrich, ed. Caister Academic Press, Norfolk, U.K.

Le Quéré, A. J. L., Deakin, W. K., Schmeisser, C., Carlson, R. W., Streit, W. R., Broughton, W. J., and Scott Forsberg, L. 2006. Structural characterization of a K-antigen capsular polysaccharide essential for normal symbiotic infection in Rhizobium sp. NGR234. J. Biol. Chem. 281:28981-28992.

Madinabeitia, N., Bellogín, R. A., Buendía-Clavería, A. M., Camacho, M., Cubo, T., Espuny, M. R., Gil-Serrano, A., de Lyra, M. C. C. P., Moussaid, A., Ollero, F. J., Soria-Díaz, M. E., Vinardell, J. M., Zeng, J., and Ruiz-Sainz, J. E. 2002. Sinorhizobium fredii HH103 has a truncated nolO gene due to a -1 frameshift mutation that is conserved among other geographically distant $S$. fredii strains. Mol. Plant-Microbe Interact. 15:150-159.

Margaret, I., Becker, A., Blom, J., Bonilla, I., Goesmann, A., Göttfert, M., Lloret, J., Mittard-Runte, V., Rückert, C., Ruiz-Sainz, J. E., Vinardell, J. M., and Weidner, S. 2011. Symbiotic properties and first analyses of the genomic sequence of the fast growing model strain Sinorhizobium fredii HH103 nodulating soybean. J. Biotechnol. 155:11-19.

Margaret-Oliver, I., Lei, W., Parada, M., Rodríguez-Carvajal, M. A., Crespo-Rivas, J. C., Hidalgo, A., Gil-Serrano, A., Moreno, J., Rodríguez-Navarro, D. N., Buendía-Clavería, A., Ollero, J., Ruiz-Sainz, J. E., and Vinardell, J. M. 2012. Sinorhizobium fredii HH103 does not 
strictly require KPS and/or EPS to nodulate Glycyrrhiza uralensis, an indeterminate nodule-forming legume. Arch. Microbiol. 194:87-102.

Mithöfer, A. 2002. Supression of plant defence in rhizobia-legume symbiosis. Trends Plant Sci. 7:440-444.

Parada, M., Vinardell, J. M., Ollero, F. J., Hidalgo, A., Guitiérrez, R., Buendía-Clavería, A.M., Lei, W., Margaret, I., López-Baena, F. J., GilSerrano, A. M., Rodríguez-Carvajal, M. A., Moreno, J., and Ruiz-Sainz, J. E. 2006. Sinorhizobium fredii $\mathrm{HH} 103$ mutants affected in capsular polysaccharide (KPS) are impaired for nodulation with soybean and Cajanus cajan. Mol. Plant-Microbe Interact. 19:43-52.

Petrovics, G., Putnoky, P., Reuhs, B., Kim, J., Thorp, T. A., Noel, K. D., Carson, R. W., and Kondorosi, A. 1993. The presence of a novel type of surface polysaccharide in Rhizobium meliloti requires a new fatty acid synthase-like genes cluster involved in symbiotic nodule development. Mol. Microbiol. 8:1083-1094.

Power, P. M., and Jennings, M. P. 2003. The genetics of glycosylation in Gram-negative bacteria. FEMS (Fed. Eur. Microbiol. Soc.) Microbiol. Lett. 218:211-222.

Prentki, P., and Krisch, H. M. 1984. In vitro insertional mutagenesis with a selectable DNA fragment. Gene 29:303-313.

Pueppke, S. G., and Broughton, W. J. 1999. Rhizobium sp. strain NGR234 and $R$. fredii USDA257 share exceptionally broad, nested host ranges. Mol. Plant-Microbe Interact. 12:293-318.

Putnoky, P., Petrovics, G., Kereszt, A., Grosskopf, E., Ha, D. T., Banfalvi, Z., and Kondorosi, A. 1990. Rhizobium meliloti lipopolysaccharide and exopolysaccharide can have the same function in the plant-bacterium interaction. J. Bacteriol. 172:5450-5458.

Puvanesarajah, V., Schell, F. M., Gerhold, D., and Stacey, G. 1987. Cell surface polysaccharides from Bradyrhizobium japonicum and a nonnodulating mutant. J. Bacteriol. 169:137-141.

Quelas, J. I., Mongiardini, E. J., Casabuono, A., López-García, S. L., Althabegoiti, M. J., Covelli, J. M., Pérez-Jiménez, J., Couto, A., and Lodeiro, A. R. 2010. Lack of galactose or galacturonic acid in Bradyrhizobium japonicum USDA110 exopolysaccharide leads to different symbiotic responses in soybean. Mol. Plant-Microbe Interact. 23:15921604.

Reuhs, B. L., Kim, J. S., Badgett, A., and Carlson, R. W. 1994. Production of cell-associated polysacharides of Rhizobium fredii USDA205 is modulated by apigenin and host root extract. Mol. Plant-Microbe Interact. 7:240-247.

Reuhs, B. L., Williams, M. N. V., Kim, J. S., Carlson, R. W., and Cote, F. 1995. Suppresion of the Fix ${ }^{-}$phenotype of Rhizobium meliloti exoB mutants by lps $Z$ is correlated to a modified expression of the K-polysaccharide. J. Bacteriol. 177:4289-4296.

Sambrook, J., Fritsch, E. F., and Maniatis, T. 1989. Molecular Cloning: A Laboratory Manual, 2nd ed. Cold Spring Harbor Laboratory, Cold Spring Harbor, NY, U.S.A.

Schäfer, A., Tauch, A., Jager, W., Kalinowski, J., Thierbach, G., and Pühler,
A. 1994. Small mobilizable multi-purpose cloning vectors derived from the Escherichia coli plasmids pK18 and pK19: Selection of defined deletions in the chromosome of Corynebacterium glutamicum. Gene 145:69-73.

Schirm, M., Soo, E. C., Aubry, A. J., Austin, J., Thibault, P., and Logan, S. M. 2003. Structural, genetic and functional characterization of the flagellin glycosylation process in Helicobacter pylori. Mol. Microbiol. 48:1579-1592.

Schoenhofen, I. C., McNally, D. J., Brisson, J. R., and Logan, S. M. 2006 Elucidation of the CMP-pseudaminic acid pathway in Helicobacter pylori: Synthesis from UDP- $N$-acetylglucosamine by a single enzymatic reaction. Glycobiology 16:8C-14C.

Simon, R. 1984. High frequency mobilization of gram-negative bacterial replicons by the in vivo constructed Tn5-Mob transposon. Mol. Gen. Genet. 196:413-420.

Simsek, S., Ojanen-Reuhs, T., Marie, C., and Reuhs, B. L. 2009. An apigenin-induced decrease in K-antigen production by Sinorhizobium sp. NGR234 is y4gM- and nodD1-dependent. Carbohydr. Res. 344:19471950

Soto, M. J., Dominguez-Ferreras, A., Perez-Mendoza, D., Sanjuan, J., and Olivares, J. 2009. Mutualism versus pathogenesis: The give-and-take in plant-bacteria interactions. Cell Microbiol. 11:381-388.

Stacey, G., McAlvin, C. B., Kim, S. Y., Olivares, J., and Soto, M. J. 2006. Effects of endogenous salicylic acid on nodulation in the model legumes Lotus japonicus and Medicago truncatula. Plant Physiol. 141:1473-1481.

Tabei, S. M. B., Hitchen, P. G., Day-Williams, M. J., Merino, S., Vart, R., Pang, P-C. Horsburgh, G. J., Vilches, S., Wilhelms, M., Tomás, J. M., Dell, A., and Shaw, J. G. 2009. An Aeromonas caviae genomic island is required for both $\mathrm{O}$-antigen lipopolysaccharide biosynthesis and flagellin glycosylation. J. Bacteriol. 191:2851-2863.

Vinardell, J. M., López-Baena, F. J., Hidalgo, A., Ollero, F. J., Bellogín, R., Espuny, M. R., Temprano, F., Romero, F., Krishnan, H. B., Pueppke, S. G., and Ruiz-Sainz J. E. 2004a. The effect of FITA mutations on the symbiotic properties of Sinorhizobium fredii varies in a chromosomalbackground-dependent manner. Arch. Microbiol. 181:144-154.

Vinardell, J. M., Ollero, F. J., Hidalgo, A., López-Baena, F. J., Medina, C., Ivanov-Vangelov, K., Parada, M., Madinabeitia, N., Espuny, M. R., Bellogín, R. A., Camacho, M., Rodríguez-Navarro, D. N., Soria-Díaz, M. E., Gil-Serrano, A. M., and Ruiz-Sainz, J. E. 2004b. NolR regulates diverse symbiotic signals of Sinorhizobium fredii HH103. Mol. PlantMicrobe Interact. 17:676-685.

Vincent, J. M. 1970. The modified Fåhraeus slide technique. Appendix III. Pages 144-145 in: A Manual for the Practical Study of Root Nodule Bacteria. J. M. Vincent, ed. Blackwell Scientific, Oxford.

Westphal, O., and Jann, K. 1965. Bacterial lipopolysaccharides, extraction with phenol-water and further application of the procedure. Meth. Carbohydr. Chem. 5:83-91. 